\title{
Ultra-Efficient Short Read Sequencing of T Cell Receptor Repertoires
}

Janelle M. Montagne ${ }^{1}$, Xuwen Alice Zheng ${ }^{1}$, lago Pinal-Fernandez ${ }^{2,3}$, Jose C. Milisenda ${ }^{4}$, Lisa

Christopher-Stine ${ }^{5}$, Thomas E. Lloyd ${ }^{3}$, Andrew L. Mammen²,3, \& H. Benjamin Larman ${ }^{1, *}$

1Division of Immunology, Pathology Department, Johns Hopkins University School of Medicine, Baltimore, MD, USA.

${ }^{2}$ Muscle Disease Unit, Laboratory of Muscle Stem Cells and Gene Regulations, National Institute of Arthritis and Musculoskeletal and Skin Diseases, National Institutes of Health, Bethesda, MD, USA.

${ }^{3}$ Department of Neurology, Johns Hopkins University School of Medicine, Baltimore, MD, USA. ${ }^{4}$ Internal Medicine Department, Hospital Clinic, Universitat de Barcelona, Barcelona, Spain and Centro de Investigación Médica en Red Enfermedades Raras.

${ }^{5}$ Division of Rheumatology, Johns Hopkins University School of Medicine, Baltimore, MD, USA.

\section{Abstract:}

T cell receptor (TCR) repertoire sequencing is increasingly employed to characterize adaptive immune responses. However, current TCR sequencing methodologies are complex and expensive, limiting the scale of feasible studies. Here we present Framework Region 3 AmplifiKation sequencing (FR3AK-seq), a simplified multiplex PCR-based approach for the ultraefficient analysis of TCR complementarity determining region 3 (CDR3) repertoires. By using minimal primer sets targeting a conserved region adjacent to CDR3, undistorted amplicons are analyzed via short read, single-end sequencing. We find that FR3AK-seq is sensitive and quantitative, performing comparably to two industry standards. FR3AK-seq was utilized to quickly and inexpensively characterize the T cell infiltrates of muscle biopsies obtained from 145 patients with idiopathic inflammatory myopathies and controls. A cluster of related TCRs was identified in samples from patients with sporadic inclusion body myositis, suggesting the presence of a shared antigen-driven response. The ease and minimal cost of FR3AK-seq removes critical barriers to routine, large-scale TCR CDR3 repertoire analyses. 


\section{Introduction:}

T cell receptor (TCR) repertoire analysis has emerged as a powerful tool for examining adaptive immune responses. TCR repertoires, generated by the process of $V(D) J$ recombination, encompass the T cell clones within a given individual or sample. The unique TCR of each clone defines its antigen specificity, and TCRs can be associated with distinct cellular phenotypes and tissue occupancy. Notably, TCR repertoires encompass dynamic populations of cells that represent past and current immune exposures and reactivities. ${ }^{1}$ Development of next generation sequencing (NGS)-based technologies over the last decade has enabled the unprecedented analysis of TCR repertoires. ${ }^{2-5}$

TCR recognition requires antigen processing and presentation of peptide epitopes on autologous major histocompatibility complex (MHC) molecules. Analysis of TCR repertoires both within and between individuals can be indicative of disease status, prior infections or immunizations, and individual-specific attributes of epitope selection. ${ }^{6-12}$ Clonally expanded or tissue-infiltrating T cell clones provide evidence of antigen-directed immune responses; integrating TCR repertoire analyses with phenotypic measurements (e.g. single cell transcriptional profiling ${ }^{13}$ or flow cytometric sorting of $\mathrm{T}$ cell subpopulations ${ }^{14,15}$ ) can further illuminate qualitative aspects of $\mathrm{T}$ cell responses (Fig 1a).

A variety of methods have been used to generate TCR libraries for NGS, including multiplex PCR, 5'-RACE, and target enrichment. ${ }^{2-5,16,17}$ Generally, these methodologies prioritize sequencing of the hypervariable complementarity determining region 3 (CDR3) of the TCR beta (TCRB) chain. The TCRB CDR3 harbors the greatest amount of sequence diversity, confers most of the antigen specificity to a TCR, and can be used as a unique surrogate for T cell clonal identity. ${ }^{18-20}$ Despite their utility, however, current repertoire sequencing approaches remain complex and expensive. These limitations have greatly hindered the utilization of TCR repertoire-based analyses, particularly for studies involving large numbers of samples. We therefore sought to develop a 
simple, quantitative, multiplex PCR-based approach that prioritizes the ultra-efficient analysis of TCRB CDR3 sequences.

The sequence diversity of the TCRB chain variable domain, which in humans is encoded by $>120$

43 unique TCRBV alleles, necessitates the use of complex primer pools for multiplex PCR amplification. Primer competition and differential amplification efficiencies distort clonal amplicon abundance, confounding quantification. ${ }^{21}$ Sophisticated techniques have been developed to computationally correct amplification bias, such as the use of spike-in library standards or the incorporation of unique molecular identifiers (UMIs). ${ }^{22-24}$ Adaptive Biotechnologies has become a current industry leader by offering a spike-in standard corrected, multiplex PCR-based assay. At a cost of $\$ 500-\$ 1100$ per sample, however, the scale of feasible studies using this assay has been greatly constrained. Unique molecular identifier (UMI) based approaches, including the Immunoverse assay (ArcherDX), provide quantitation and enhanced sequence accuracy by resolving amplification and sequencing errors. ${ }^{23-28}$ However, UMI approaches typically require multi-day protocols, complicated analytical pipelines, and deeper sequencing to obtain sufficient sampling of distorted libraries. ${ }^{17,29}$ By designing maximally compact primer sets and a streamlined workflow, we have essentially eliminated PCR amplification bias while maintaining high sequence level accuracy. Lower sequencing depth requirements, coupled with CDR3 analysis via singleend, short-read (100 nucleotide) sequencing, dramatically reduces the cost associated with this approach to TCR repertoire analysis.

Here, we benchmark our simplified multiplex PCR-based assay, which we call Framework Region 3 AmplifiKation Sequencing (FR3AK-seq), against two different industry standards for quantitative TCR repertoire sequencing: Adaptive Biotechnologies' multiplex PCR-based hsTCRB immunoSEQ assay and ArcherDX's UMI-based Immunoverse HS TCR assay. We found that FR3AK-seq data, which was analyzed using open-source software, was in excellent agreement 
biopsied muscle tissue from a cohort of 145 patients with idiopathic inflammatory myopathies and controls.

\section{Results:}

\section{Minimal primer sets targeting the TCRB framework region 3 (FR3) efficiently amplify CDR3} sequences

We hypothesized that minimizing the number of potentially competing $\vee$-gene primers, while also minimizing amplicon length, would maximize the efficiency of TCRB CDR3 region amplification. To identify candidate primer binding sequences upstream and proximal to CDR3, we constructed a phylogenetic tree of all functional TCRB FR3 regions available from the Immunogenetics (IMGT/GENE-DB) reference directory. ${ }^{30}$ This revealed a high degree of sequence conservation within the 3' terminus of FR3 (Fig 1b). This homology may reflect a critical role for these sequences in the optimal presentation of the CDR3 loop. The 3' 20 nucleotides of these IMGT FR3s were therefore extracted and used as target primer binding sequences. Remarkably, the 128 functional TCRBV alleles reported by IMGT are represented by only 47 distinct 3'-terminal 20-mers. Beyond their sequence homology, additional advantages of targeting these sequences include minimal CDR3 amplicon length (and in turn optimal amplification efficiency) and the ability to sequence using short (100 nucleotide) single end reads initiated proximal and upstream of CDR3. We refer to this approach to TCRB CDR3 analysis as FR3 AmplifiKation sequencing, or "FR3AK-seq".

We developed a greedy algorithm to automate the design of three candidate sets of primers, each targeting the 47 distinct TCRB FR3 3' 20-mers (Fig S1): one primer set lacks any universal bases or mismatches ("Full" set), one primer set lacks universal bases but allows a single mismatch to occur ("1MM" set), and one primer set contains parsimonious incorporation of up to 3 universal 
89 (inosine) bases and allows one mismatch ("Compact" set). No mismatches were permitted within

90 the five nucleotides of the $3^{\prime}$ end of the primers, as a precaution to minimize interference with

91 polymerase extension. ${ }^{31-33}$ The Full set consists of 47 primers (equal to the number of unique

92 FR3 3' 20-mers), the 1MM set consists of 34 primers, and the Compact set consists of 20 primers

93 (Table S1). We calculated the expected efficiency of each primer to amplify each FR3 sequence;

94 these efficiencies are visualized in the form of a clustered heatmap (Fig 1c). Importantly, each of

95 the 47 unique 3' FR3 20 mers are predicted to be amplified efficiently by at least one primer in 96 each set. 

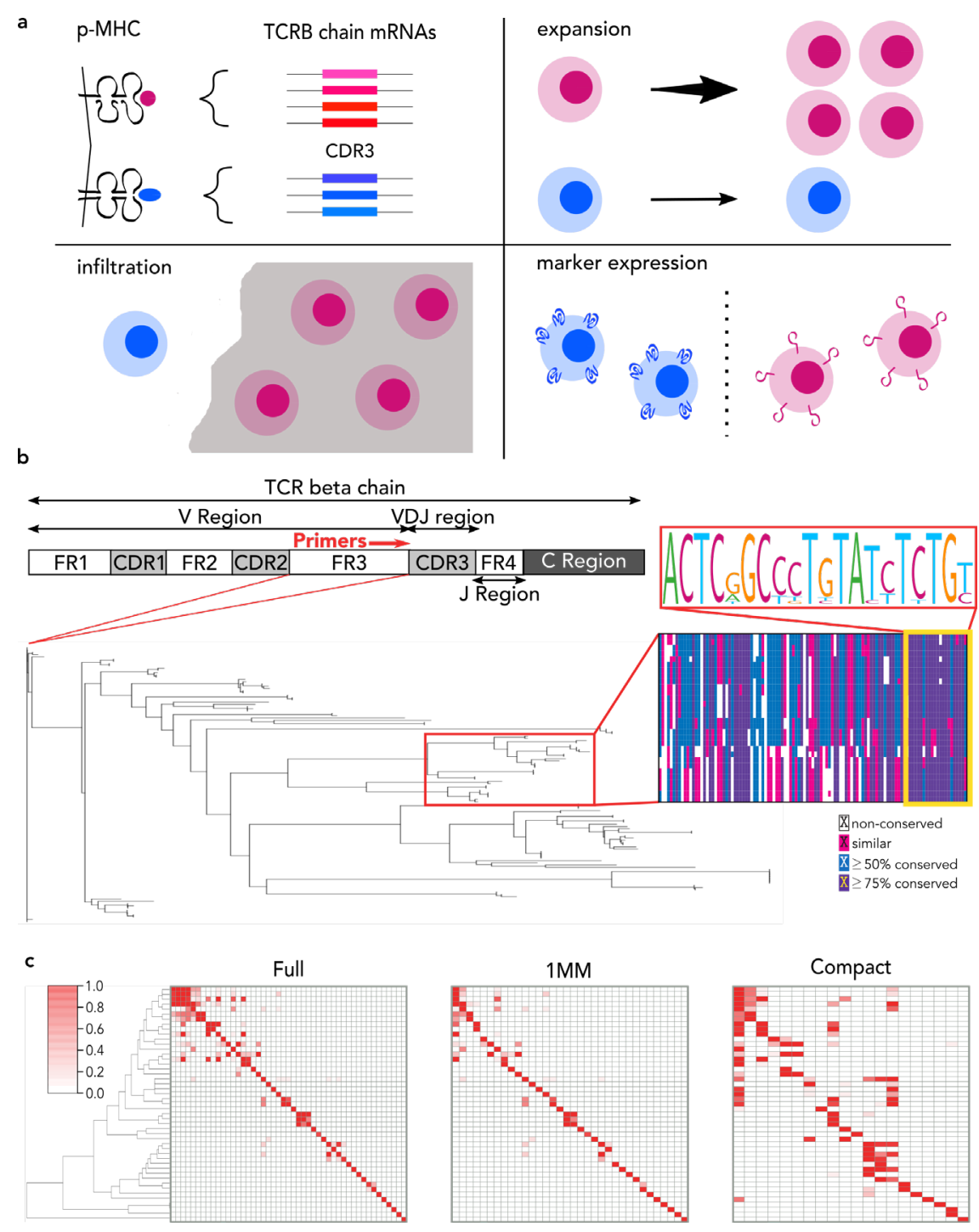

Figure 1: Utility of T cell receptor beta (TCRB) chain sequencing and FR3AK-seq multiplex PCR primer design. a. TCRB chain sequencing can be used to (i) identify related CDR3s that may share antigen specificity, (ii) detect expanded clones, (iii) identify tissue infiltrating clones, and (iv) link CDR3 sequences with $T$ cell phenotypes. b. A schematic of the TCRB chain. A neighbor joining phylogenetic tree of FR3s extracted from the 128 functional human TCRBV alleles in the IMGT/GENE-DB reference directory and multiple sequence alignment from a dominant FR3 sequence cluster (red box on tree) identifies homology within the 3' 20 nucleotides (yellow box). c. Clustered heatmaps for the Full, 1MM, and Compact primer sets showing primer amplification efficiencies for each primer across each of the 47 unique 3' 20 nucleotides of the human TCRBV FR3 region. Inosines were considered exact matches for the Compact set. Y axis: 47 unique TCRBV FR3s. X axis: primers. The order of the primers in each heatmap can be found in Table S1. The order of unique TCRBV FR3s is identical to the order of the Full primers for all heatmaps. 


\section{TCRB FR3 primers amplify CDR3 sequences with minimal bias}

112 Each primer was tested separately and within its set for the ability to produce amplicon from

113 peripheral blood mononuclear cell (PBMC) cDNA. Agarose gel electrophoresis revealed a PCR

114 product at the expected size of $\sim 220$ base pairs (Fig S2a). Importantly, incorporation of the

115 inosine base did not prevent amplification by the KAPA Fast HotStart Taq DNA Polymerase. While

116 lower PCR primer annealing temperature might increase off-target priming, it may also reduce

117 unwanted bias in amplification from primers containing a single nucleotide mismatch. ${ }^{34}$ We

118 therefore utilized gradient PCR to assess the effect of annealing temperature on the number of

119 unique CDR3 sequences detected using the Compact primer set. As expected, more unique

120 CDR3 clones were recovered at lower annealing temperatures (Fig S2b), and a similar trend was observed for the $1 \mathrm{MM}$ primer set. The annealing temperature that produced the maximum number of unique clones was identified for each set as follows: Full: $52^{\circ} \mathrm{C}, 1 \mathrm{MM}: 47^{\circ} \mathrm{C}$, Compact: $42^{\circ} \mathrm{C}$. Use of a hemi-nested RT-PCR strategy (Fig S3) resulted in no apparent amplification of non-

TCRB sequences, even at the lowest PCR annealing temperature.

We next quantified PCR amplification bias inherent to the three primer sets. cDNA first underwent 20 cycles of PCR. An aliquot of this product was diluted $2^{10}$-fold and then subjected to 10 more cycles of PCR; sequencing was then performed on both amplicons and the resulting data sets compared to each other. In this experiment, significant per-cycle amplification bias would manifest as discordance. However, the concordance remains high for all three primer sets, suggesting that FR3AK-seq primers negligibly bias the CDR3 repertoire during cycles of PCR amplification $(\rho=$ 0.997 for the Full primer set and $\rho=0.998$ for the $1 \mathrm{MM}$ primer set, Fig $2 \mathrm{a} ; \rho=0.997$ for the Compact primer set, Fig S2c).

We then performed rarefaction analysis to determine the relationship between RNA input amount, sequencing depth, and the number of unique clones detected using FR3AK-seq. We found that 
136 (Fig 2b), providing the rationale for RNA input amounts and sequencing depths used in

137 subsequent analyses. We also assessed the sensitivity of FR3AK-seq to detect rare clones by 138 spiking varying amounts of monoclonal Jurkat RNA (from 1 up to 10,000 cellular equivalents) into 139 a background of $400 \mathrm{ng}$ PBMC RNA ( 20\% T cells). We found that FR3AK-seq detected the 140 Jurkat CDR3 sequence at all input amounts at the expected abundances, while the abundance 141 of the top three PBMC T cell clones remained constant across the dilution series (Fig 2c). The 142 Jurkat sequence abundance was used to calculate cellular equivalents for the top three PBMC 143 clones in each sample. Notably, the coefficient of variation for these cellular equivalents was 144 below $1 \%$ in the 1,000 Jurkat cell equivalent spike-in samples (CV $=0.897 \%)$. This provided the 145 basis for the subsequent use of 1,000 cellular equivalents of spike-in cells. 
a

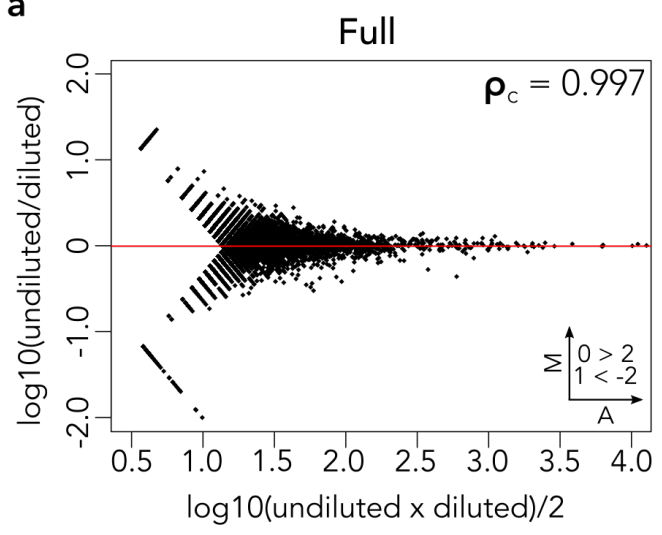

b

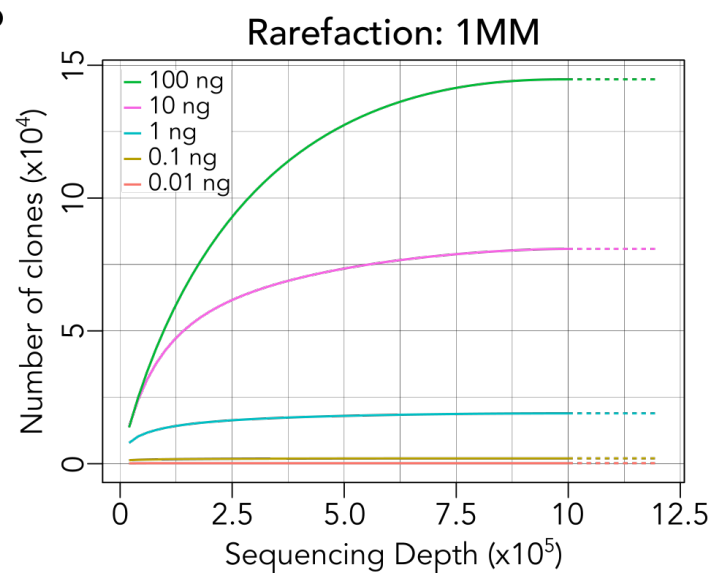

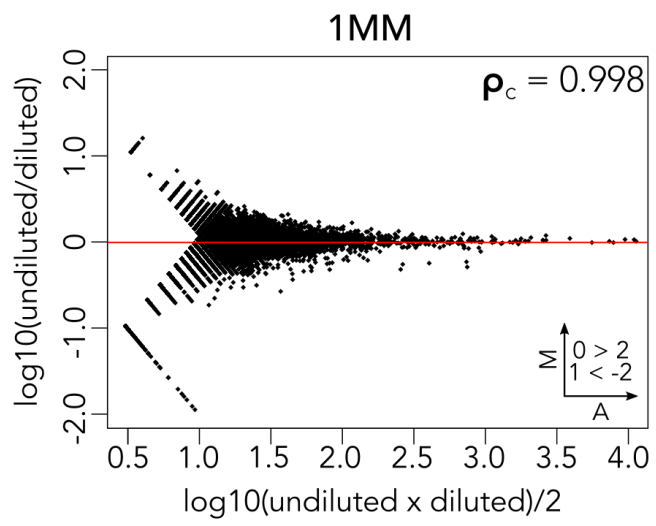

C

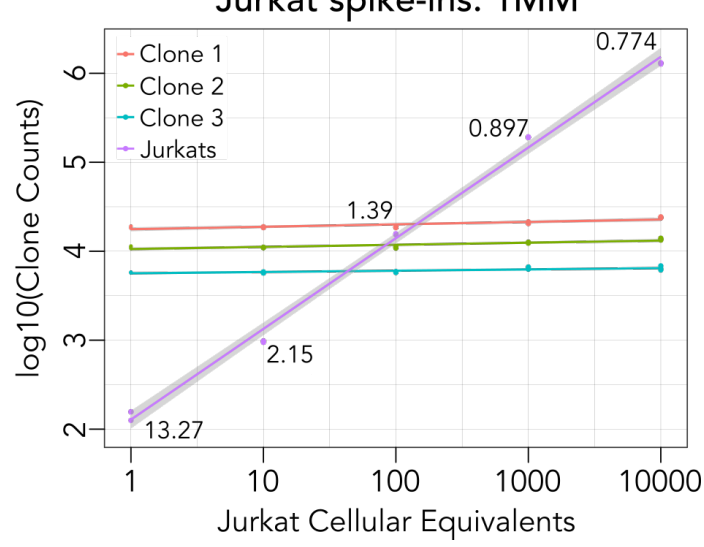

Figure 2: FR3AK-seq multiplex PCR performance. a. MA plots of $2^{10}$ dilution experiments for the Full and $1 \mathrm{MM}$ primer sets demonstrated high linear concordance (Full: 0.997, 1MM: 0.998, Compact in Fig S2c), indicating negligible PCR bias. Clones with $\geq 10$ counts in either dataset were compared. Insets indicate number of clones above or below $Y$ axis limits (set to 2 and -2 for visualization). b. Rarefaction analysis using $T$ cell RNA purified from PBMCs showed the relationship between RNA input, number of clones detected, and sequencing depth using FR3AK-seq. c. The spiked-in Jurkat CDR3 sequence was detected at the expected abundances using FR3AK-seq (performed in triplicate). Estimated abundances of the top three $T$ cell clones were consistent among triplicates and across spiked-in samples. $95 \%$ confidence intervals for regression lines and coefficients of variation for the cellular equivalents calculated for the $T$ cell clones are shown. 

and $10 \%$ Donor B RNA (sample "C"), were used to generate cDNA for benchmarking studies against the current multiplex PCR-based industry standard, the immunoSEQ hsTCRB "Deep Resolution" sequencing service offered by Adaptive Biotechnologies. Separate cDNA aliquots were also subjected to FR3AK-seq analysis using each of the three primer sets. The open source software MiXCR v2.1.11 was used to define and quantify CDR3 sequences from both assays for direct comparison. ${ }^{35}$ The technical reproducibility of the immunoSEQ assay was quantified by abundances in sample $C$ (concordance correlation coefficient, $\rho=0.989$, left panel Fig $3 a$ ). The same analysis was applied to the FR3AK-seq data sets, which were generated using each of the three FR3 primer sets. Equally high measures of internal concordance were observed $(\rho=0.990$ for the $1 \mathrm{MM}$ primer set, right panel Fig 3a; $\rho=0.990$ for the Full primer set and $\rho=0.987$ for the Compact primer set, Fig S4a). Importantly, the concordance between immunoSEQ and FR3AKseq measurements of CDR3 abundance was also very high ( $\rho=0.975$, Fig 3b, Fig S4b), 177 providing further evidence that FR3AK-seq amplifies CDR3s with negligible bias. The majority of even moderately abundant immunoSEQ-defined CDR3 sequences were also detected using any

179 of the three FR3 primer sets (Fig 3c). Additionally, the 9:1 mixture composed of cells from Donor 180 A and Donor B (sample C) was used to determine quantification accuracy of the FR3 primer sets 181 relative to the immunoSEQ assay (Fig 3d, Fig S4c). These data indicate that all three FR3 primer 182 sets provide CDR3 quantification comparable to the industry standard immunoSEQ assay, with the $1 \mathrm{MM}$ primer set performing most accurately. 
a

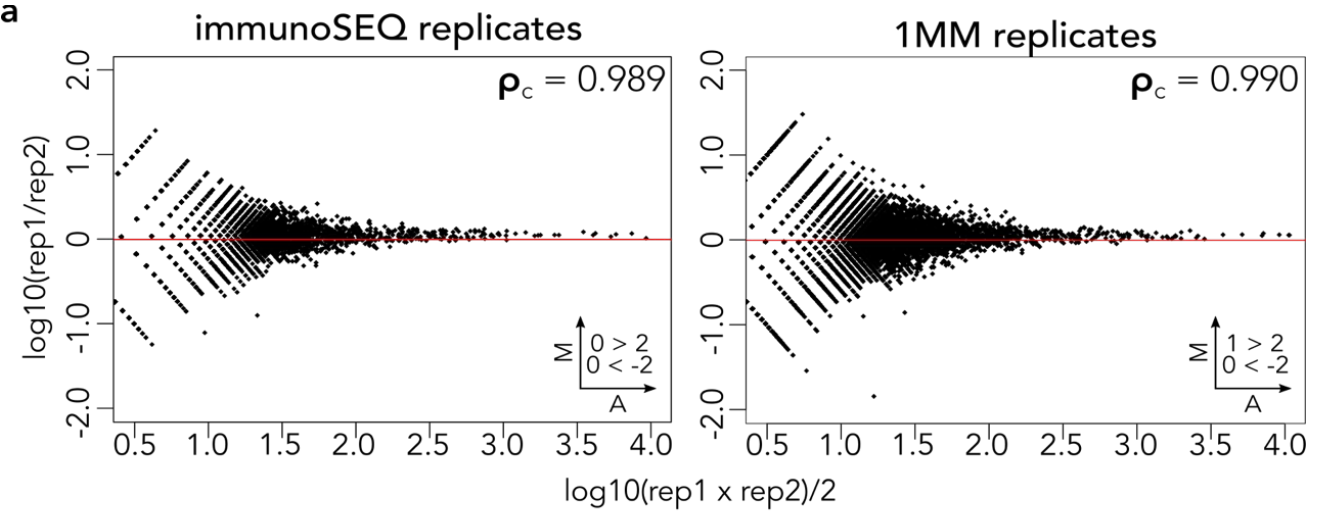

b

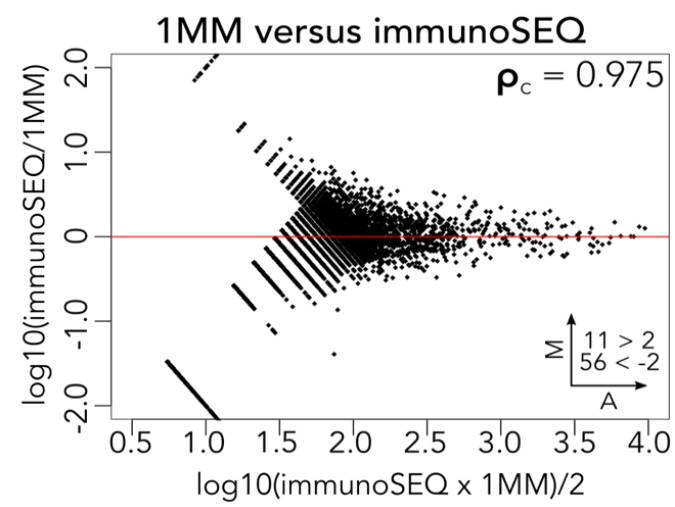

d

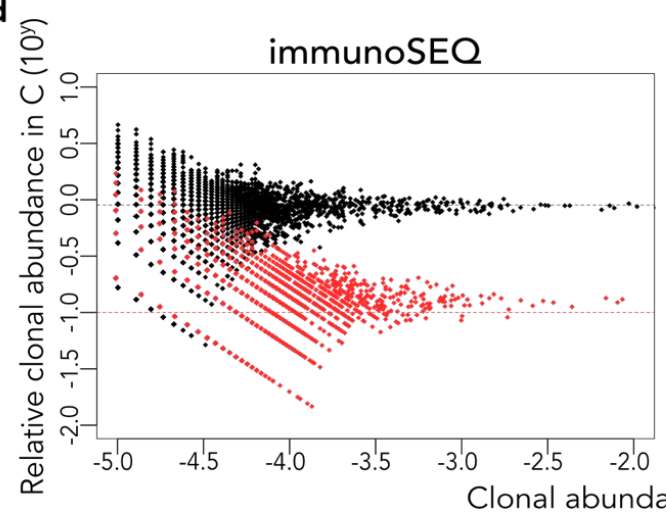

C

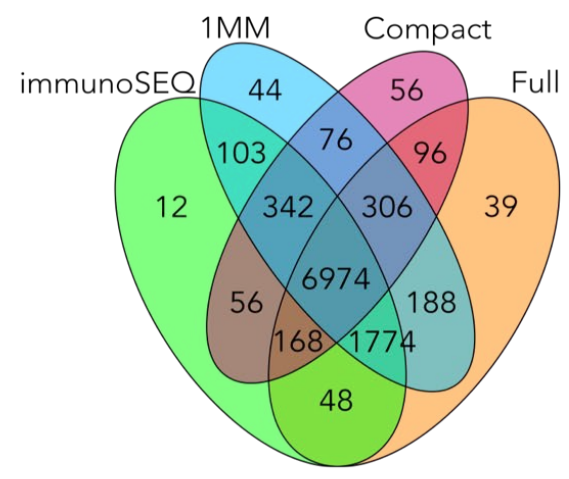

$1 \mathrm{MM}$

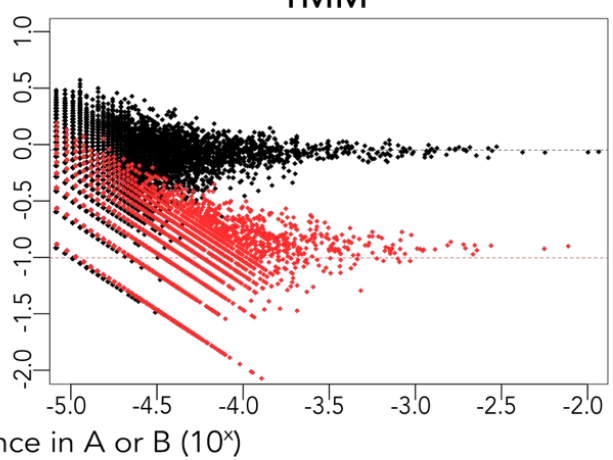

Figure 3: FR3AK-seq performs comparably to the multiplex PCR-based immunoSEQ assay from Adaptive Biotechnologies. a. MA plots comparing technical replicates of the immunoSEQ and $1 \mathrm{MM}$ FR3AK-seq assays. b. MA plot comparing the 1 MM FR3AK-seq assay against the immunoSEQ assay. Clones with $\geq 10$ counts in either dataset were included. c. A Venn diagram shows overlapping and non-overlapping CDR3 sequences detected using immunoSEQ and all three FR3AK-seq primer sets. CDR3 sequences were included in this analysis if they had a clone count $\geq 10$ in any of the four data sets. $d$. Relative frequencies of Donor A (black points) and Donor B (red points) in sample $C$ determined using the immunoSEQ assay or the 1MM FR3AK-seq assay. Insets in $\mathbf{a}$ and $\mathbf{b}$ indicate number of clones above or below $Y$ axis limits (set to 2 and -2 for visualization). 


\section{FR3AK-seq performs comparably to a unique molecular identifier (UMI)-based industry} standard

To assess whether FR3AK-seq achieves results comparable to UMI-based methodologies, we compared the FR3AK-seq $1 \mathrm{MM}$ and immunoSEQ datasets to one obtained using ArcherDX's UMI-based Immunoverse HS TCR assay. PBMC RNA from the same samples A, B, and C described above were subjected to Immunoverse analysis for comparison with the FR3AK-seq and immunoSEQ datasets. The technical reproducibility of the Immunoverse assay was similar to that of both immunoSEQ and FR3AK-seq ( $\rho=0.967$, Fig 4a). Additionally, concordance between FR3AK-seq and Immunoverse was high ( $\rho=0.900$, upper panel Fig 4b). Relatively high concordance was also observed when comparing immunoSEQ to Immunoverse $(\rho=0.886$, lower panel Fig 4b). Crucially, the majority of clones detected by the Immunoverse assay were also detected by both immunoSEQ and FR3AK-seq (Fig 4c). These data demonstrate that FR3AKseq has a high sensitivity for detecting clones of the correct sequence $(4352 / 4403,98.8 \%$ of total clones detected by Immunoverse). Strikingly, a large number (2803) of clones were detected by both immunoSEQ and FR3AK-seq but not Immunoverse. Rarefaction analysis of the FR3AK-seq and Immunoverse datasets explained this difference in clonal detection sensitivity, in that FR3AKseq sampled more clones at all sequencing depths (Fig 4d). Although FR3AK-seq achieves better coverage of the repertoire than Immunoverse across sequencing depths, we wanted to quantify how many of the FR3AK-seq detected clones may be the result of false discovery. To address this question, we performed FR3AK-seq $1 \mathrm{MM}$ analysis of 1,000 cellular equivalents of Jurkat cell RNA in triplicate. Since the Jurkat cell line is monoclonal, the frequencies of subdominant clones, presumably generated by PCR or sequencing errors, can be used to assess the rate of false positive discovery. 99.98\% of MiXCR-defined CDR3s mapped to the correct reported Jurkat TCRB sequence in each sample. We found an average of 50 non-Jurkat clones across triplicates, of which only one was moderately abundant ( $\geq 10$ clone counts) in each. This secondary clone 
219 was the same between replicates and represented on average $0.0067 \%$ of total MiXCR-defined

220 CDR3s. Using default MiXCR settings, FR3AK-seq analysis is therefore associated with a very

221 low rate of false discovery due to PCR or sequencing errors. Modification of MiXCR thresholds

222 can be used to adjust the stringency with which these subdominant clones are grouped. We also

223 compared the CDR3 lengths of clones detected using each sequencing platform, and found that

224 FR3AK-seq's short (100 nucleotide) reads did not bias the distribution of CDR3 lengths recovered

225 (Fig 4e). 
a

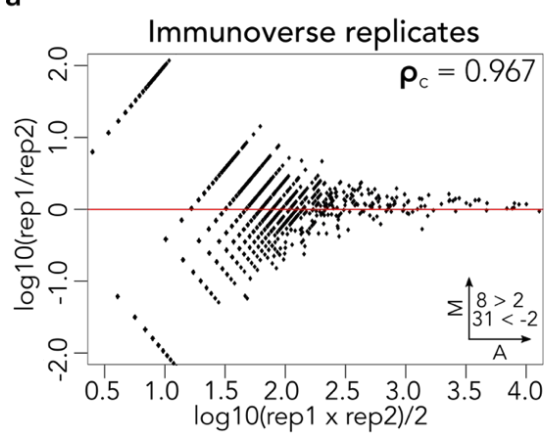

b
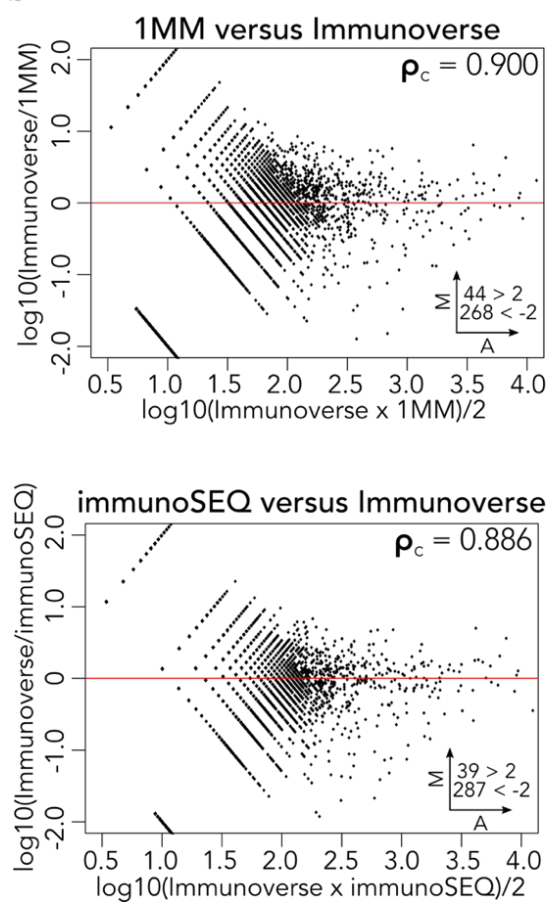

c

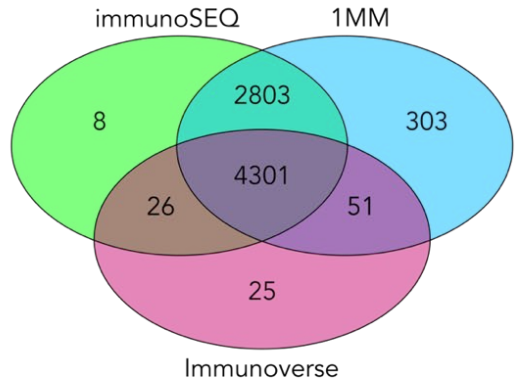

d
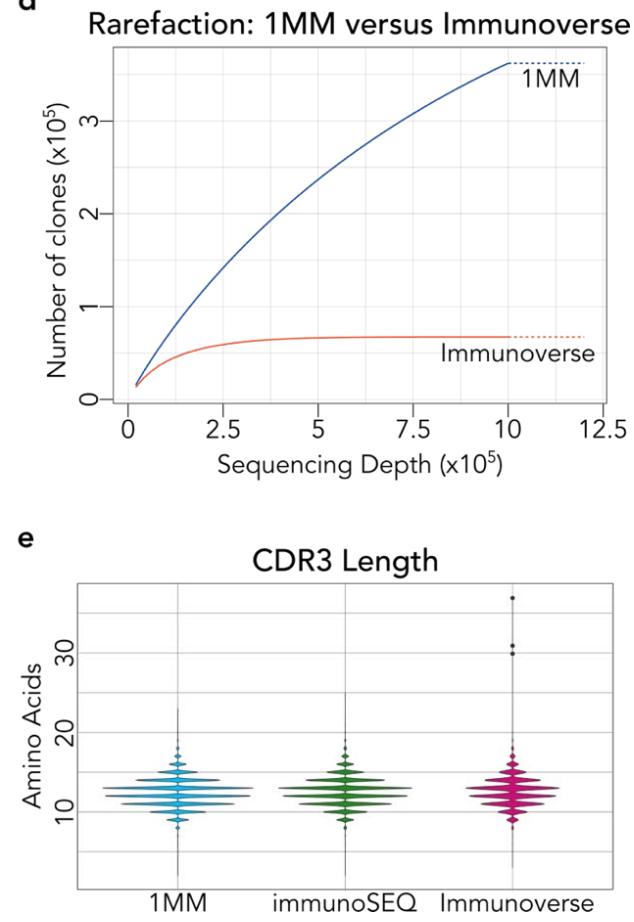

Figure 4: FR3AK-seq performs comparably to the UMI-based ArcherDX Immunoverse assay. a. MA plot comparing Immunoverse technical replicates. b. MA plots comparing the 1MM FR3AK-seq assay against the Immunoverse assay (top panel) and Adaptive Biotechnologies' immunoSEQ assay against the Immunoverse assay (bottom panel). Clones with $\geq 10$ counts in either dataset were included (using prededuplicated counts for the Immunoverse dataset).

c. A Venn diagram shows overlapping and nonoverlapping CDR3 sequences detected using Immunoverse, immunoSEQ, and the 1MM FR3AK-seq primer set. CDR3 sequences were included in this analysis if they had a clone count of $\geq 10$ in any of the three data sets. $\mathbf{d}$. Rarefaction analysis comparing the $1 \mathrm{MM}$ FR3AK-seq assay to the Immunoverse assay using $100 \mathrm{ng}$ of T cell RNA ( 250,000 cells) for 1MM FR3AK-seq analysis and $200 \mathrm{ng}$ of T cell RNA ( $\sim 500,000$ cells) for Immunoverse analysis. 1MM: $\sim 1.2 \times 10^{6}$ reads, Immunoverse: $\sim 1.4 \times 10^{6}$ reads. e. Violin plots comparing CDR3 lengths captured by the short-read 1MM FR3AK-seq versus longer-read immunoSEQ and Immunoverse assays. Insets in $\mathbf{a}$ and $\mathbf{b}$ indicate number of clones above or below $\mathbf{Y}$ axis limits (set to 2 and -2 for visualization). 


\section{FR3AK-seq enables inexpensive cohort-scale repertoire studies}

242 Muscle biopsies from 145 patients with idiopathic inflammatory myopathies (IIMs, 124) as well as

243 healthy controls (9) and non-IIM controls (12) were analyzed using the 1MM primer set at a total

244 cost of $\sim \$ 20$ per sample (Table S2). IIM patients included those with dermatomyositis (DM, 40),

245 immune-mediated necrotizing myopathy (IMNM, 49), inclusion body myositis (IBM, 14), and anti-

246 synthetase syndrome (ASyS, 21) (Table S3). For absolute T cell number estimation, 1,000 cell

247 equivalents of RNA derived from a clonal tumor infiltrating $\mathrm{T}$ cell line ${ }^{36}$ were spiked into each

248 sample after RNA purification. Aggregated CD4 and CD8 sequencing reads from RNA-seq

analysis of the same samples (performed separately and reported elsewhere) tightly correlated

with FR3AK-seq based estimates of cellular equivalents (Fig 5a). In subsequent analyses, CDR3

sequences present at levels at or below one cell equivalent per biopsy were considered

agreement with previous immunohistochemical analyses, IBM biopsies contained particularly high levels of T cell infiltrates. ${ }^{37-39}$ We determined this to be the case both in terms of absolute T cell number and clonal diversity (Fig 5b, Fig S5a). No distinct patterns of $\mathrm{J}$ gene usage were found among patient subgroups (Fig S6a), and CDR3 hydrophobicity and lengths were similar between patient subgroups (Fig S6b-c).

The open source software GLIPH (grouping of lymphocyte interactions by paratope hotspots) ${ }^{10}$ was next used to search for clusters of related CDR3 sequences within the aggregated set of non-bystander CDR3s (Table S4). 143 clusters composed of sequences contributed by at least 3 individuals were identified. We first examined clusters that had a disproportionate number of sequences contributed by single individuals. Fig 5c provides an example of a cluster dominated by related CDR3 sequences contributed by a single ASyS patient. Compared to CDR3 sequences 
266 significantly increased, suggestive of a polyclonal, shared antigen-driven expansion. These

267 results suggest that GLIPH is able to cluster related CDR3 sequences that have been detected

268 and quantified using FR3AK-seq.

269 We next determined whether any of the GLIPH clusters were composed of sequences contributed

270 disproportionately by individuals from one of the IIM subgroups. Indeed, we found a GLIPH cluster

271 that was composed exclusively of sequences contributed by IBM patients. Specifically, 5 of the

27212 IBM patients with non-bystander T cells contributed at least one sequence to this cluster ( $p=$

$2731.4 \times 10^{-6}$, Fig 5d). Remarkably, all CDR3 sequences in this IBM cluster are linked to a single J-

274 chain (TRBJ2-2*01), providing additional support for shared antigen recognition. Taken together,

275 this study demonstrates the utility of FR3AK-seq in probing T cell responses at cohort scale. 
a

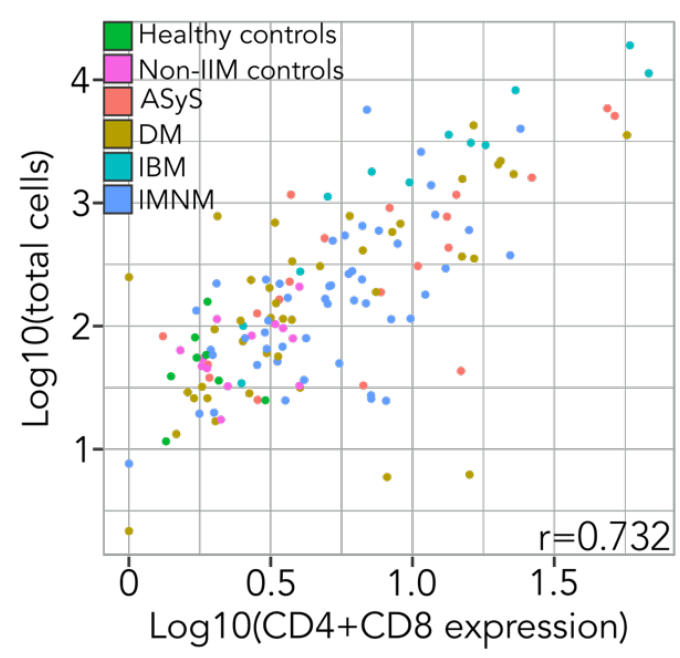

C

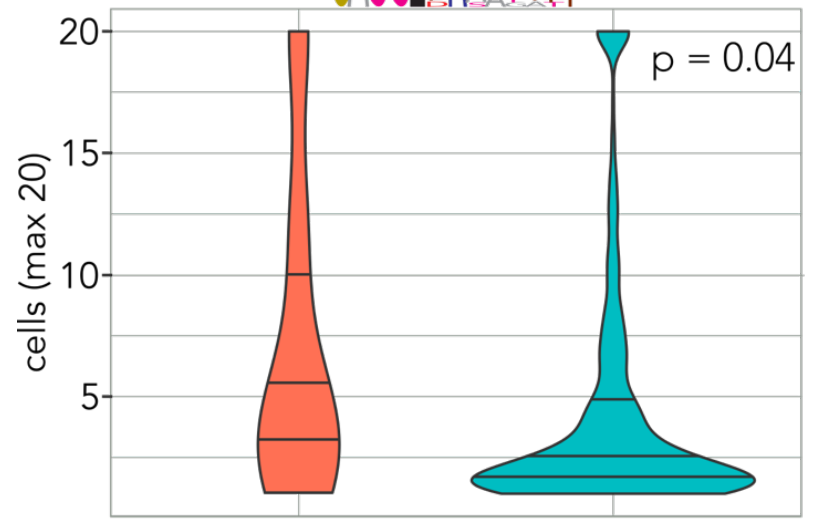

ASyS within cluster

ASyS unclustered b

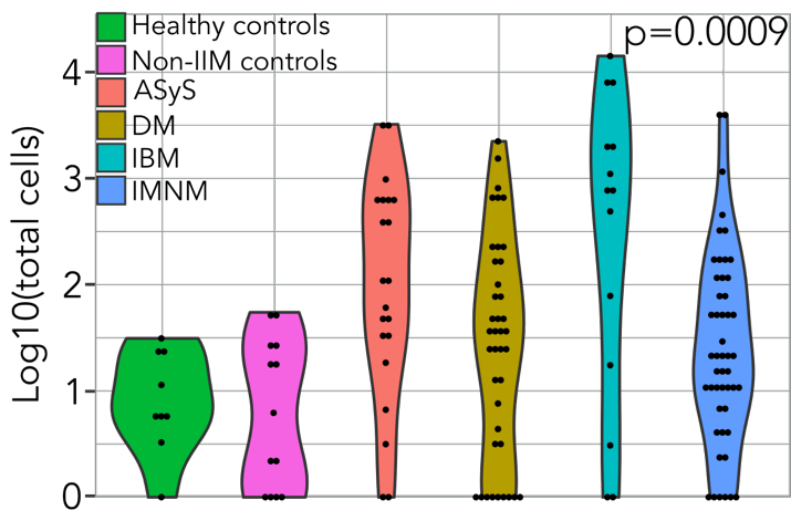

d

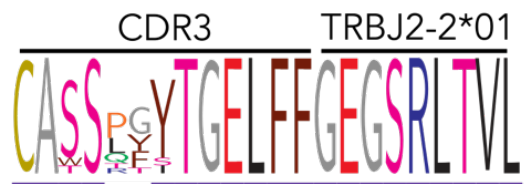

CASSPFYTGELFFGEGSRLTVL

CASSPYYT GELFFGEGSRLTVL

CASSPYYT GELFFGEGSRLTVL

CASSQFYTGELFFGEGSRLTVL

CASSQYYTGELFFGEGSRLTVL

CASSRFYTGELFFGEGSRLTVL

CATSPTYTGELFFGEGSRLTVL

CAWSTGYTGELFFGEGSRLTVL-IBM 42

CASSLGSTGELFFGEGSRLTVL-IBM 92

CASSPGYTGELFFGEGSRLTVL

CASSLGYT GELFFGEGSRLTVL

IBM 13

CASSLGITGELFFGEGSRLTVL-IBM 27

Xnon-conserved

X similar

$\underline{X} \geq 50 \%$ conserved

$\mathbb{\mathrm { X }} \geq 75 \%$ conserved

Figure 5: FR3AK-seq detects related T cell responses in subsets of patients with idiopathic inflammatory myopathies. a. Scatterplot of estimated T cell counts per patient versus CD4 and CD8 expression levels obtained from bulk mRNA-seq. Each patient data point is colored according to their IIM association. Pearson correlation coefficient ( $r$ ) is shown. b. Distributions of cell counts per patient for each IIM and controls. Kruskal-Wallis p-value is provided. c. A CDR3 cluster enriched for sequences from a single patient with ASyS was identified using GLIPH software $\left(p=1.4 \times 10^{-7}\right)$. The amino acid sequence logo of the CDR3 region is shown above the violin plot. The clones within this cluster are more expanded than corresponding unclustered clones from the same patient. Mann-Whitney $p=0.04$. Cell counts were set to a maximum of 20 for visualization. d. An IBM-exclusive cluster was also identified using GLIPH, encompassing 5 of 12 IBM patients who had non-bystander T cell infiltrates $\left(41.7 \%, p=1.4 \times 10^{-6}\right)$. Multiple sequence alignment (using MUSCLE) is shown for the corresponding MiXCR-defined CDR3s and the $J$ chain allele (TRBJ2-2*01). 


\section{Discussion}

Although the utility of TCR repertoire sequencing to characterize T cell responses has been well established, the lack of a streamlined, quantitative, inexpensive, and non-proprietary assay has limited the scope and scale of feasible studies. By rationally designing minimal sets of primers that target the 3' terminus of FR3, we have developed a multiplex PCR-based approach for ultraefficient library preparation and sequencing of TCRB CDR3 repertoires. By minimizing amplification bias (via reduction of primer number and amplicon length), the resulting sequencing libraries quantitatively capture clonal abundance distributions with an accuracy comparable to both multiplex PCR-based and UMI-based industry standards. While the library preparation and sequencing strategy presented here already bring the per-sample cost to $\sim$ \$20 (Table S2), we declining sequencing costs will likely enable another $\sim 10$-fold reduction in per-sample cost. In addition to reducing the overall cost of obtaining CDR3 sequences, we have developed the FR3AK-seq workflow to require minimal expertise, effort, and time. Quantitative sequencing libraries can easily be prepared within a single day. Comparisons of protocols and cost between FR3AK-seq, immunoSEQ, and Immunoverse are summarized in Table S5.

Our approach to TCRB repertoire analysis should be generalizable to additional immune receptor types, as well as to those of non-human species (see Table $\mathbf{S 6}$ for Mus musculus TCRB primers). Although these mouse primers have not been as extensively validated as the human set, they have been confirmed to efficiently amplify CDR3 sequences from mouse tissues. We have additionally used the same FR3 primer design and analysis principles to target human TCR alpha,

312 gamma, and delta repertoires, although these primers have not yet been validated (Table S7).

313 We have also designed a set of TCRB $\mathrm{J}$ region reverse primers (Table S8) that perform 314 comparably to our constant region reverse primer using cDNA templates $(\rho=0.949$, Fig S7). 315 These will be potentially useful for analysis of FFPE samples which suffer from extensive RNA 
degradation. Interestingly, during the preparation of this manuscript, the Euroclonality Group

317 (creators of the BIOMED2 primer set ${ }^{40}$ ) published a new set of TCR primers for next-generation

318 sequencing, including some that are designed in the $5^{\prime}$ portion of $\mathrm{FR} 3,{ }^{41}$ providing additional

319 validation for an FR3-targeted approach to TCR repertoire sequencing.

$320 V$ gene usage is often of interest, for example to detect usage skewing and for functional studies

321 involving TCR cloning. FR3AK-seq prioritizes small amplicons to reduce both PCR bias and cost.

322 Therefore, by design, amplicons do not contain easily recoverable $\mathrm{V}$ gene sequence information.

323 However, it is theoretically possible to make inferences on each CDR3's associated $V$ genes,

324 based on the pattern of FR3 primer usage. We expect these inferences to be more accurate for

325 more abundant clones. When analysis of $\mathrm{V}$ gene usage is desired, complementary techniques

326 (e.g. 5'RACE) can be parsimoniously utilized to capture this information. One may wish to use

327 FR3AK-seq to track unique CDR3 sequences of interest over time, across tissues, and/or after

328 FACS analysis - these FR3AK-seq detected CDR3 sequences can then be readily associated

329 with a $\mathrm{V}$ gene by merging data sets.

330 To demonstrate the use of FR3AK-seq for efficient cohort scale analysis of TCRB CDR3

331 repertoires, we characterized the muscle-infiltrating $\mathrm{T}$ cells present within muscle biopsies

332 obtained from 145 inflammatory muscle disease patients and controls. TCRB CDR3 sequence

333 clustering indicated both donor and disease specific antigen-driven T cell responses. Importantly,

334 the majority of T cell clones detected in IBM muscle biopsies were not hyperexpanded, in contrast

335 to the hypothesis that infiltrating IBM $\mathrm{T}$ cells originate from a clonal $\mathrm{T}$ cell large granular

336 lymphocytic leukemia (TLGLL) (Fig S5b). ${ }^{42,43}$ Future studies will utilize FR3AK-seq in combination

337 with in vitro stimulation to characterize the antigenic determinants of these clonal clusters. 


\section{Methods:}

\section{FR3 primer design}

341 FR3 sequences from all functional human TCRB $V$ alleles were downloaded from the IMGT/LIGMDB reference directory (non-functional and pseudogenes were excluded). ${ }^{30}$ Multiple sequence msa. ${ }^{44}$ The 3' 20 nucleotides of the TCRB chain FR3s were subsequently used to design three sets of primers as described in the text. We automated design of the $1 \mathrm{MM}$ and the Compact 347 primer sets with an algorithm outlined in Fig S1, available on Github 348 (https://github.com/jmmontagne/FR3AK-seq). Human TCRB primer sequences can be found in

Table S1.

PBMC preparation, T cell purification, RNA extraction, and cDNA synthesis 
363

364

365

366

367

368

369

370

371

372

373

374

375

376

377

378

379

380

381

382

383

384

385

386

ng of RNA from each sample was input into the Immunoverse assay. The concordance between FR3AK-seq and Immunoverse remained high despite the use of PBMC RNA rather than T cell RNA for the Immunoverse assay. All primer sequences are provided in Table S1.

\section{Polymerase Chain Reaction (PCR) and sequencing library preparation}

$100 \mathrm{ng}$ TCRB chain cDNA was used as template for PCR with KAPA2G Fast Multiplex Mix (Kapa Biosystems, Wilmington, MA). Forward TCRB FR3 primers from the Full, 1MM, or Compact primer sets were used with a single nested TCR beta chain constant region reverse primer at 0.2 $\mu \mathrm{M}$ per primer. Samples underwent 30 cycles of PCR for visualization by agarose gel electrophoresis, or 20 cycles for NGS library preparation ("PCR1"). We compared the performance of Herculase II Fusion DNA polymerase (Agilent, Santa Clara, CA) and KAPA2G Fast Multiplex Mix for PCR1 and found that both enzymes perform comparably $(\rho=0.966$, Fig S8). Herculase II is therefore an acceptable enzyme alternative for PCR1 if desired.

20 cycles of PCR2 were performed on PCR1 product (2 $\mu \mathrm{L}$ of PCR1 added to $18 \mu \mathrm{L}$ of PCR2 master mix, which contained $0.25 \mu \mathrm{M}$ each i5 and i7 sample barcoding primers) to incorporate sample barcodes and Illumina sequencing adaptors using Herculase II Fusion DNA Polymerase. Equal volumes of barcoded PCR2 products (5 $\mu \mathrm{L}$ each) were pooled and PCR column purified using QIAquick PCR Purification Kit (Qiagen). Libraries were quantified using KAPA Library Quantification Kit for Illumina Platforms (Kapa Biosystems). Barcoding primer sequences can be found in Supplementary File 1. See Fig S3 for a schematic of our sequencing strategy.

\section{Sequencing and CDR3 analysis}

Sequencing was performed on an Illumina NextSeq 500 (immunoSEQ benchmarking comparisons), MiSeq (Immunoverse samples), or HiSeq 2500 (IBM muscle biopsy analysis). CDR3s were identified and quantified using MiXCR v2.1.11 software ${ }^{35}$ with default parameters except as noted in Table S9. Data obtained from Adaptive Biotechnologies' immunoSEQ assay 
were re-analyzed using MiXCR v2.1.11 and identical parameters for comparison to our own data.

For reanalysis, full nucleotide sequences for each CDR3 from the Adaptive Biotechnologies

ImmunoSEQ dataset were expanded to repeat as many times as indicated by the corresponding

"count" column. This file, with each clonal nucleotide sequence represented as many times as its

"count" column, was converted to FASTA format for compatibility with MiXCR. The sequences

obtained from ArcherDX's Immunoverse assay were expanded to repeat as many times as their

pre-deduplicated clone counts and then matched back to their deduplicated clone counts after reanalysis with MiXCR v2.1.11. Clone count cutoffs for each analysis are as described in the

figure legends and refer to the pre-deduplicated counts for the Immunoverse assay (Note:

deduplicated clone counts were used for all comparisons, while pre-deduplicated counts were

only used to filter the dataset to $\geq 10$ counts). Information regarding the total number of clones,

the number of singletons, and the number of clones occurring at $\geq 10$ counts for FR3AK-seq, immunoSEQ, and Immunoverse can be found in Table S10.

Repertoire analysis using muscle biopsies from patients with idiopathic inflammatory

RNA isolated from muscle biopsies taken from 145 IIM patients or controls was reverse transcribed, PCR amplified, sequenced, and analyzed as described above. Healthy control muscle biopsies were obtained from healthy volunteers at the Skeletal Muscle Biobank of the University of Kentucky, while non-IIM controls were obtained for clinical purposes at the Johns 406 Hopkins Neuromuscular Pathology Laboratory and were normal after pathologic evaluation. We 407 added 1,000 cell equivalents of RNA from a clonal tumor infiltrating T cell line as a spike-in to 408 each sample. ${ }^{36}$ Sequencing of 6 spike-in only samples provided the CDR3 sequences to remove 409 from downstream analyses of samples containing muscle biopsy RNA. The spike-in counts were 410 used for cell number quantification within patient samples, which distinguished 'bystander' versus 
411 'non-bystander' T cell clones. One non-IIM control muscle biopsy was sequenced in duplicate,

412 making the total number of samples 146.

413 CDR3 sequences obtained from these samples were analyzed for disease-specific clusters using 414 the GLIPH 1.0 group discovery algorithm (see Table S9 for parameters). ${ }^{10}$ To determine the 415 statistical significance of each cluster, we performed chi-square analysis on all clusters with at 416 least three contributing individuals, followed by Benjamini-Hochberg multiple comparison 417 correction. This analysis was performed for both the number of sequences contributed by each 418 disease subgroup to each cluster, as well as the number of patients in each disease group 419 represented within each cluster. P-values $\leq 0.05$ after multiple test correction were considered statistically significant.

\section{Author Contributions:}

423 Conceptualization and experimental design: J.M.M., H.B.L.; performing experiments: J.M.M.; data 424 analysis and software: J.M.M., X.A.Z.; human specimen procurement and analysis: I.P-F., J.C.M., 425 L.C-S., T.E.L., A.L.M., H.B.L.; data interpretations: J.M.M., X.A.Z., T.E.L., A.L.M., H.B.L.; paper 426 writing: J.M.M., H.B.L. All authors reviewed the paper.

\section{Competing Interests:} receptor based cellular therapies. 
434 The authors would like to thank Dr. Erik Wright for his advice on primer design, Dr. Suzanne L.

435 Topalian for the TIL1558 cell line, and Dr. Maximilian F. Konig for his review of the manuscript.

436 We would also like to thank the Johns Hopkins Medical Institute Deep Sequencing and Microarray

437 Core Facility and the Johns Hopkins Institute of Genetic Medicine Genetics Resources Core

438 Facility. This work was supported by NIH grant U24AI118633 and a Prostate Cancer Foundation

439 Young Investigator Award. 


\section{References:}

1. Attaf, M., Huseby, E. \& Sewell, A. K. $\alpha \beta$ T cell receptors as predictors of health and disease. Cell. Mol. Immunol. 12, 391-399 (2015).

2. Freeman, J. D., Warren, R. L., Webb, J. R., Nelson, B. H. \& Holt, R. A. Profiling the T-cell receptor beta-chain repertoire by massively parallel sequencing. Genome Res. 19, 18171824 (2009).

3. Robins, H. S. et al. Comprehensive assessment of T-cell receptor beta-chain diversity in alphabeta T cells. Blood 114, 4099-4107 (2009).

4. Weinstein, J. A., Jiang, N., White, R. A., Fisher, D. S. \& Quake, S. R. High-throughput sequencing of the zebrafish antibody repertoire. Science 324, 807-810 (2009).

5. Boyd, S. D. et al. Measurement and clinical monitoring of human lymphocyte clonality by massively parallel VDJ pyrosequencing. Sci. Transl. Med. 1, 12ra23 (2009).

6. Muraro, P. A. et al. T cell repertoire following autologous stem cell transplantation for multiple sclerosis. J. Clin. Invest. 124, 1168-1172 (2014).

7. Gros, A. et al. PD-1 identifies the patient-specific CD8 ${ }^{+}$tumor-reactive repertoire infiltrating human tumors. J. Clin. Invest. 124, 2246-2259 (2014).

8. Beausang, J. F. et al. T cell receptor sequencing of early-stage breast cancer tumors identifies altered clonal structure of the T cell repertoire. Proc. Natl. Acad. Sci. U. S. A. 114, E10409-E10417 (2017).

9. Emerson, R. O. et al. Immunosequencing identifies signatures of cytomegalovirus exposure history and HLA-mediated effects on the T cell repertoire. Nat. Genet. 49, 659-665 (2017).

10. Glanville, J. et al. Identifying specificity groups in the T cell receptor repertoire. Nature 547, 94-98 (2017).

11. Dash, P. et al. Quantifiable predictive features define epitope-specific T cell receptor repertoires. Nature 547, 89-93 (2017).

12. DeWitt, W. S. et al. Human T cell receptor occurrence patterns encode immune history, genetic background, and receptor specificity. eLife 7, (2018).

13. Han, A., Glanville, J., Hansmann, L. \& Davis, M. M. Linking T-cell receptor sequence to functional phenotype at the single-cell level. Nat. Biotechnol. 32, 684-692 (2014).

14. Morris, $\mathrm{H}$. et al. Tracking donor-reactive T cells: Evidence for clonal deletion in tolerant kidney transplant patients. Sci. Transl. Med. 7, 272ra10 (2015).

15. Theil, A. et al. T cell receptor repertoires after adoptive transfer of expanded allogeneic regulatory T cells. Clin. Exp. Immunol. 187, 316-324 (2017).

16. Mamedov, I. Z. et al. Quantitative tracking of T cell clones after haematopoietic stem cell transplantation. EMBO Mol. Med. 3, 201-207 (2011).

17. Rosati, E. et al. Overview of methodologies for T-cell receptor repertoire analysis. BMC Biotechnol. 17, 61 (2017).

18. Rudolph, M. G., Stanfield, R. L. \& Wilson, I. A. How TCRs bind MHCs, peptides, and coreceptors. Annu. Rev. Immunol. 24, 419-466 (2006).

19. Turner, S. J., Doherty, P. C., McCluskey, J. \& Rossjohn, J. Structural determinants of T-cell receptor bias in immunity. Nat. Rev. Immunol. 6, 883-894 (2006).

20. Miles, J. J., Douek, D. C. \& Price, D. A. Bias in the $\alpha \beta$ T-cell repertoire: implications for disease pathogenesis and vaccination. Immunol. Cell Biol. 89, 375-387 (2011).

21. Kebschull, J. M. \& Zador, A. M. Sources of PCR-induced distortions in high-throughput sequencing data sets. Nucleic Acids Res. 43, e143 (2015).

22. Carlson, C. S. et al. Using synthetic templates to design an unbiased multiplex PCR assay. Nat. Commun. 4, 2680 (2013).

23. Shugay, M. et al. Towards error-free profiling of immune repertoires. Nat. Methods 11, 653-655 (2014). 
24. Peng, Q., Vijaya Satya, R., Lewis, M., Randad, P. \& Wang, Y. Reducing amplification artifacts in high multiplex amplicon sequencing by using molecular barcodes. BMC Genomics 16, 589 (2015).

25. Vander Heiden, J. A. et al. pRESTO: a toolkit for processing high-throughput sequencing raw reads of lymphocyte receptor repertoires. Bioinformatics 30, 1930-1932 (2014).

26. Shugay, M. et al. VDJtools: Unifying Post-analysis of T Cell Receptor Repertoires. PLoS Comput. Biol. 11, (2015).

27. Oakes, T. et al. Quantitative Characterization of the T Cell Receptor Repertoire of Naïve and Memory Subsets Using an Integrated Experimental and Computational Pipeline Which Is Robust, Economical, and Versatile. Front. Immunol. 8, (2017).

28. Ma, K.-Y. et al. Immune Repertoire Sequencing Using Molecular Identifiers Enables Accurate Clonality Discovery and Clone Size Quantification. Front. Immunol. 9, 33 (2018).

29. Egorov, E. S. et al. Quantitative profiling of immune repertoires for minor lymphocyte counts using unique molecular identifiers. J. Immunol. Baltim. Md 1950 194, 6155-6163 (2015).

30. Giudicelli, V., Chaume, D. \& Lefranc, M.-P. IMGT/GENE-DB: a comprehensive database for human and mouse immunoglobulin and T cell receptor genes. Nucleic Acids Res. 33, D256-261 (2005).

31. Simsek, M. \& Adnan, H. Effect of single mismatches at 3'-end of primers on polymerase chain reaction. J. Sci. Res. Med. Sci. 2, 11-14 (2000).

32. Wu, J.-H., Hong, P.-Y. \& Liu, W.-T. Quantitative effects of position and type of single mismatch on single base primer extension. J. Microbiol. Methods 77, 267-275 (2009).

33. Wright, E. S. et al. Exploiting extension bias in polymerase chain reaction to improve primer specificity in ensembles of nearly identical DNA templates. Environ. Microbiol. 16, 13541365 (2014).

34. Ishii, K. \& Fukui, M. Optimization of annealing temperature to reduce bias caused by a primer mismatch in multitemplate PCR. Appl. Environ. Microbiol. 67, 3753-3755 (2001).

35. Bolotin, D. A. et al. MiXCR: software for comprehensive adaptive immunity profiling. Nat. Methods 12, 380-381 (2015).

36. Deng, L. et al. Structural basis for the recognition of mutant self by a tumor-specific, MHC class II-restricted T cell receptor. Nat. Immunol. 8, 398-408 (2007).

37. Arahata, K. \& Engel, A. G. Monoclonal antibody analysis of mononuclear cells in myopathies. I: Quantitation of subsets according to diagnosis and sites of accumulation and demonstration and counts of muscle fibers invaded by T cells. Ann. Neurol. 16, 193-208 (1984).

38. Fyhr, I. M., Moslemi, A. R., Lindberg, C. \& Oldfors, A. T cell receptor beta-chain repertoire in inclusion body myositis. J. Neuroimmunol. 91, 129-134 (1998).

39. Cavazzana, I., Fredi, M., Selmi, C., Tincani, A. \& Franceschini, F. The Clinical and Histological Spectrum of Idiopathic Inflammatory Myopathies. Clin. Rev. Allergy Immunol. 52, 88-98 (2017).

40. van Dongen, J. J. M. et al. Design and standardization of PCR primers and protocols for detection of clonal immunoglobulin and T-cell receptor gene recombinations in suspect lymphoproliferations: Report of the BIOMED-2 Concerted Action BMH4-CT98-3936. Leukemia 17, 2257-2317 (2003).

41. Brüggemann, M. et al. Standardized next-generation sequencing of immunoglobulin and Tcell receptor gene recombinations for MRD marker identification in acute lymphoblastic leukaemia; a EuroClonality-NGS validation study. Leukemia 33, 2241-2253 (2019).

42. Greenberg, S. A., Pinkus, J. L., Amato, A. A., Kristensen, T. \& Dorfman, D. M. Association of inclusion body myositis with T cell large granular lymphocytic leukaemia. Brain 139, 1348-1360 (2016). 
43. Greenberg, S. A. et al. Highly differentiated cytotoxic T cells in inclusion body myositis. Brain J. Neurol. (2019) doi:10.1093/brain/awz207. multiple sequence alignment. Bioinforma. Oxf. Engl. 31, 3997-3999 (2015). 


\section{SUPPLEMENTARY FIGURES:}

a

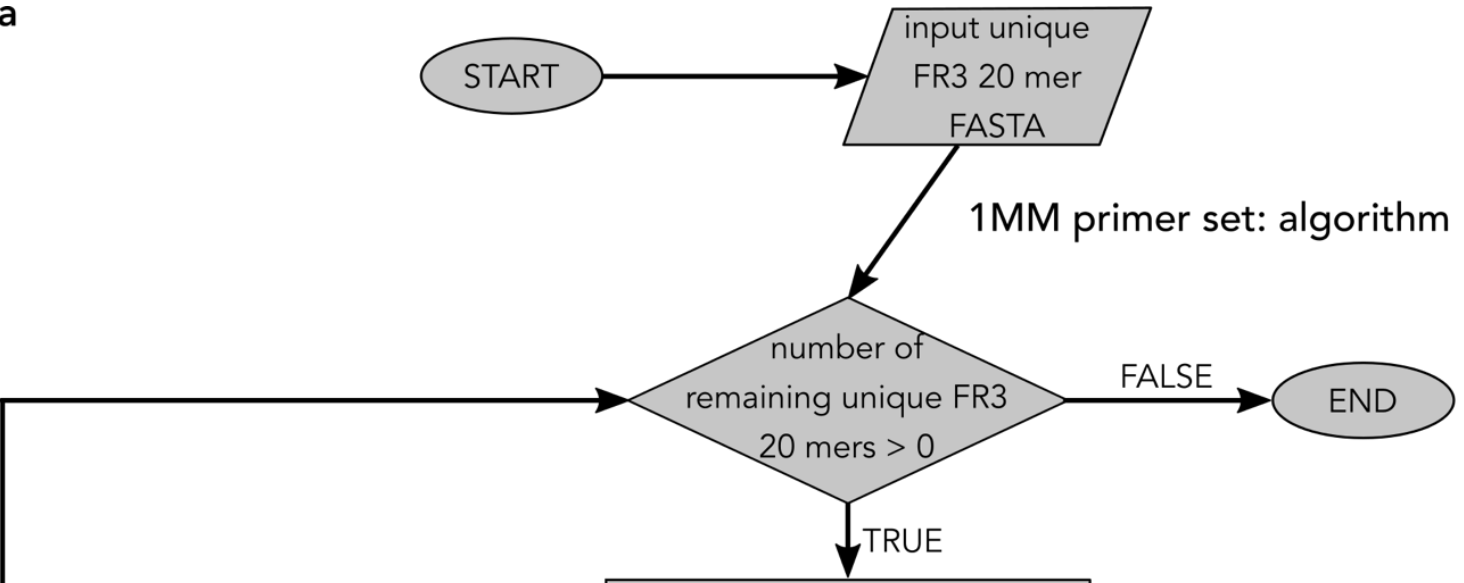

calculate $n$ t frequency

at each position of remaining

unique FR3 20 mers

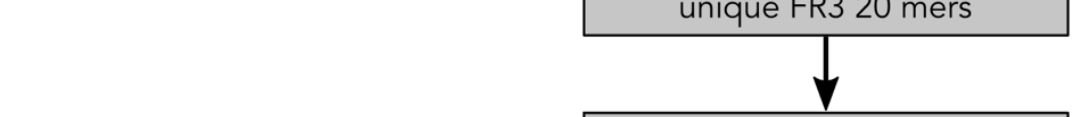

determine max nt frequency

\& set matching primer position

to that $\mathrm{nt}$ (tie: set most $5^{\prime} \mathrm{nt}$ ) 
bioRxiv preprint doi: https://doi.org/10.1101/494062; this version posted February 5, 2020. The copyright holder for this preprint (which was not certified by peer review) is the author/funder, who has granted bioRxiv a license to display the preprint in perpetuity. It is made available under aCC-BY-NC-ND 4.0 International license.

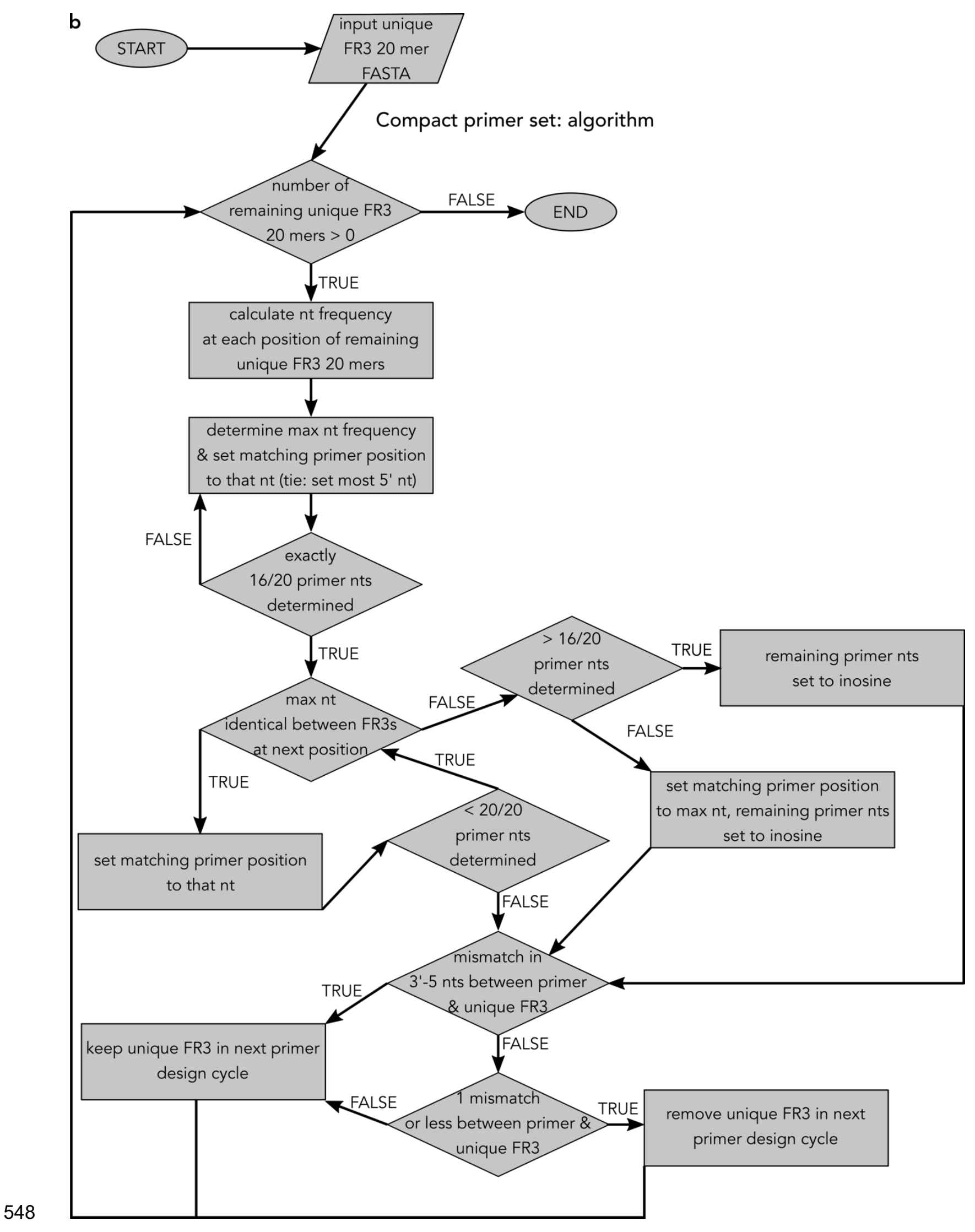


549 Figure S1: FR3AK-seq primer design algorithm schematic. a. 1MM primer set design algorithm. Input is a

550 FASTA formatted file containing each unique FR3 20-mer nucleotide (nt) sequence. Nt frequencies at each

551 of the 20 FR3 positions were calculated. The position with the maximum nt frequency in the unique FR3

552 20-mers was used and the corresponding position in the primer was set to that $\mathrm{nt}$. In the case of ties, the

553 most 5 ' position was set first. Once all 20 nts of the primer were determined, unique FR3 20-mers were

554 removed from the next round of primer design only if they: i) did not have a mismatch in the most 3'-5 nts

555 (as described in the text) and ii) had 1 mismatch or an exact match to the designed primer. The primer

556 design loop continued until no unique FR3 20-mer sequences remained. b. Compact primer set design

557 algorithm. Primers were designed as in a until 16/20 primer nts were determined. At this point, if the position

558 with the maximum nt frequency in the unique FR3 20-mers was identical to the number of remaining FR3

55920 -mers, then these nts were set to these positions. If they were not and exactly 16/20 nts in the primer

560 were already determined, then the nt with the maximum frequency was set to the corresponding primer

561 position and the remaining $3 \mathrm{nt}$ positions in the primer were set to inosines. If they were not and $>16 / 20 \mathrm{nts}$

562 in the primer were already determined, then the remaining nt positions were set to inosines. In this way, we

563 allowed for up to 3 inosines and 1 mismatch. Once all $20 \mathrm{nts}$ of the primer were determined, the remaining

564 design was identical to a, where we considered each inosine a match to any nt in the FR3 regardless of its

565 position in the primer. 
a

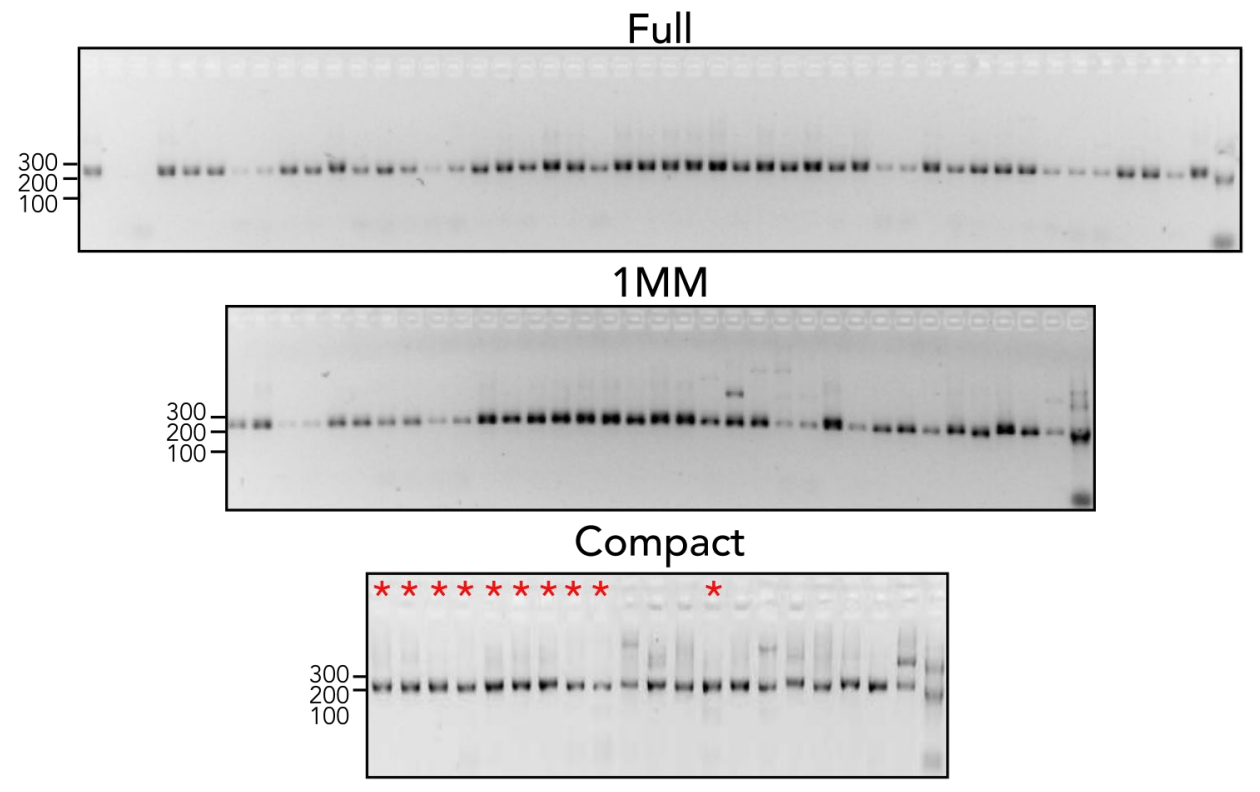

b

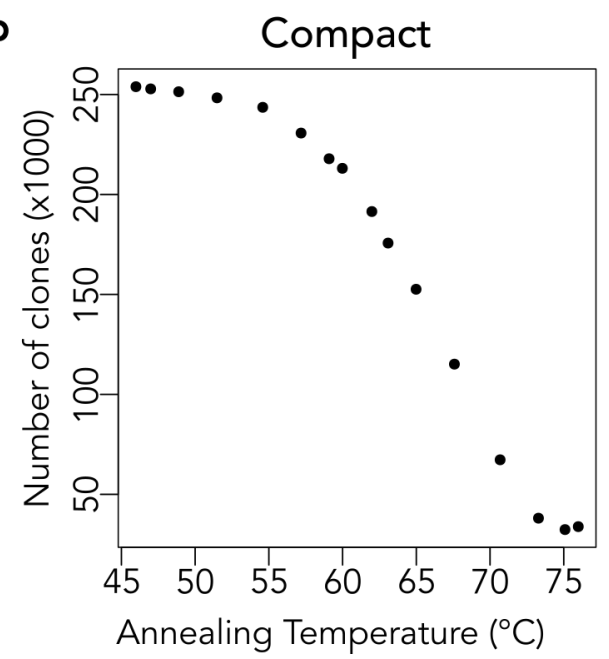

C

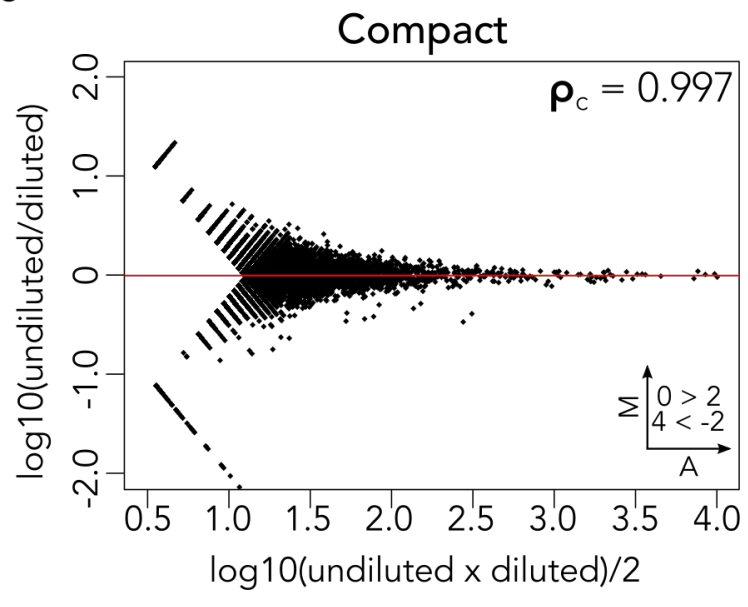

Figure S2: FR3AK-seq multiplex PCR performance. a. Individual primers from all three sets produce amplicons of the expected size from human PBMC cDNA ( 220 bp). Asterisks indicate inosine-containing

571 primers. Order of primers can be found in Table S1. b. The number of clones detected versus annealing

572 temperature using the Compact primer set is shown. A similar trend was observed for the $1 \mathrm{MM}$ primer set.

573 To account for differences in number of reads between samples, FASTQ sequencing files were trimmed to

574 identical line numbers before analysis. c. MA plot of $2^{10}$ dilution experiment for the Compact primer set

575 demonstrated high linear concordance $(\rho=0.997)$, indicating negligible PCR bias. Clones with $\geq 10$ counts

576 in either dataset were compared. Insets indicate number of clones above or below $Y$ axis limits (set to 2

577 and -2 for visualization). 


\section{TCRB chain mRNA}

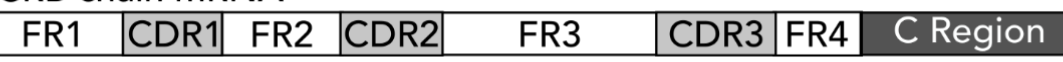

a

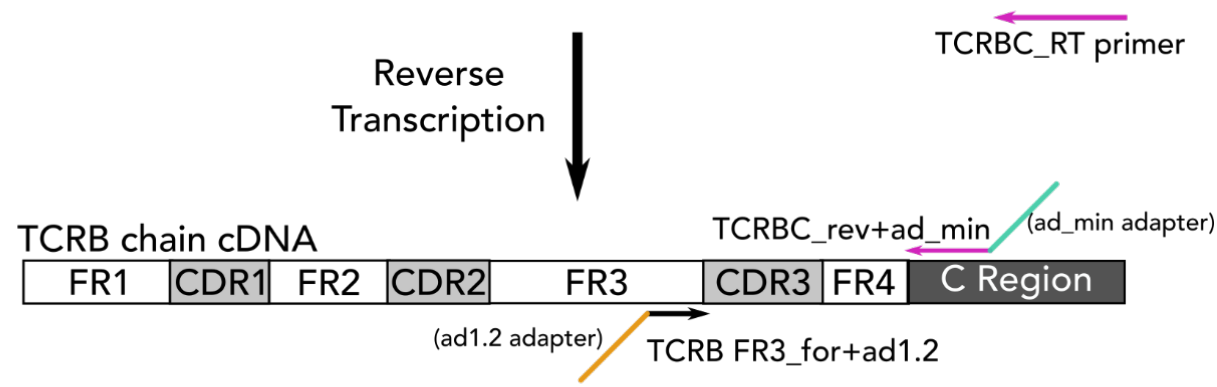

b

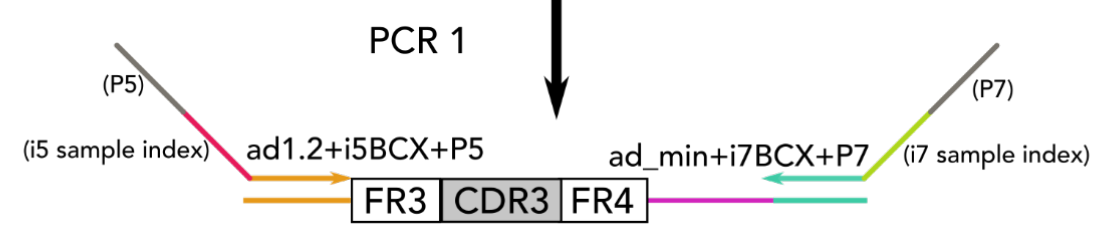

c

PCR 2

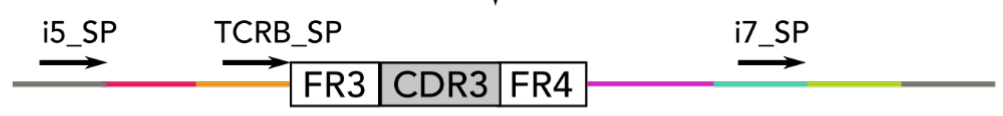

d

Figure S3: FR3AK-seq dual index sequencing strategy. a. Reverse transcription using a TCRB constant region primer generates cDNA for use as template in b. PCR1 using our forward TCRB FR3 primers and a hemi-nested TCRB constant region reverse primer. FR3 primers have 5' ad1.2 adapter sequences and the constant region primer has a 5' ad_min adapter sequence. c. PCR2 using PCR1 product as a template and indexed ad1.2 and ad_min primers, including P5 and P7 adapters for Illumina sequencing. Samples are mixed upon completion of PCR2 prior to d. Next Generation Sequencing (NGS): Illumina 100-base singleend reads along with index 5 (i5) and index 7 (i7) reads. Dual indexes are used for demultiplexing reads

586 from each sample and can be found in Supplementary File S1. No index read mismatches were permitted 587 during sample demultiplexing. Primer and adapter sequences can be found in Table S1. 
a

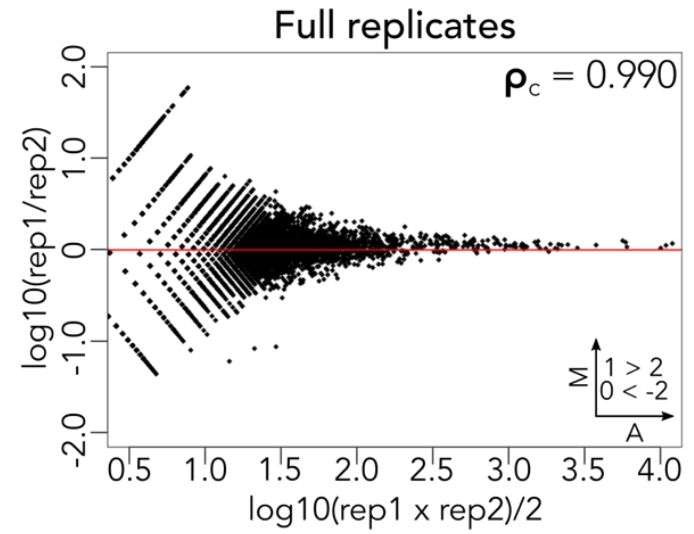

b

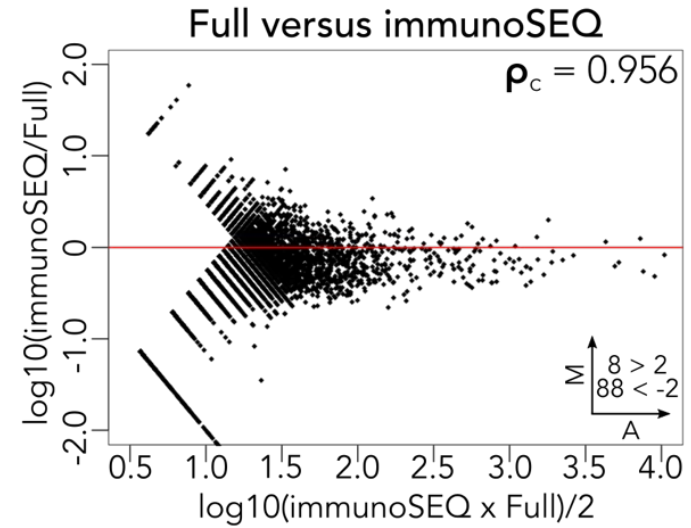

C

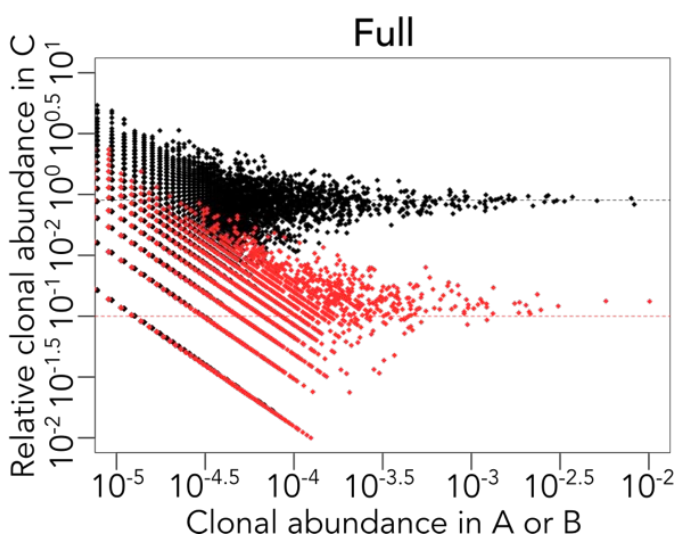

Compact replicates
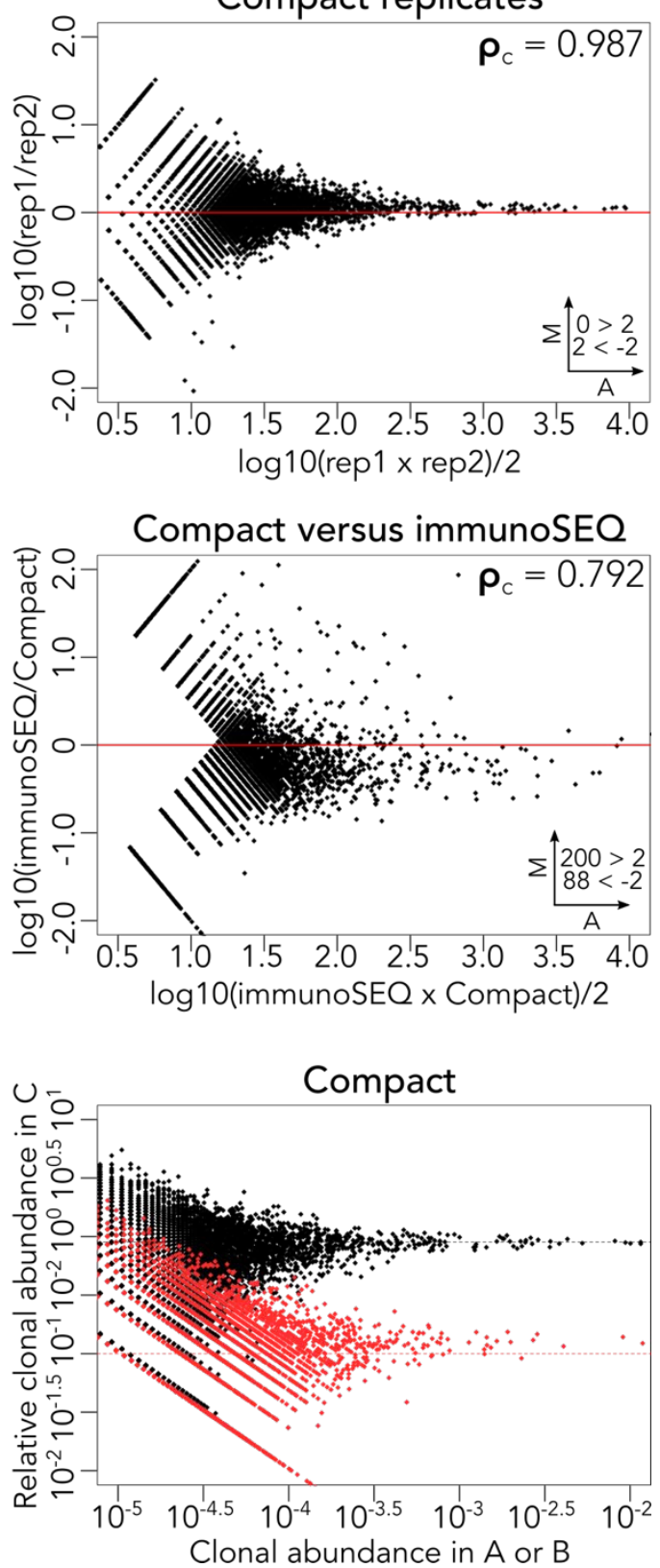

Figure S4: FR3AK-seq Full and Compact primer sets perform comparably to immunoSEQ. a. MA plots showing technical replicates of the Full (left panel) and Compact (right panel) FR3AK-seq assays. b. MA plot comparing the Full (left panel) and Compact (right panel) FR3AK-seq assay against the immunoSEQ assay. Clones with $\geq 10$ counts in either dataset were included. c. Relative frequencies of Donor A (black points) and Donor B (red points) in sample C determined using the Full (left panel) and Compact (right panel) FR3AK-seq assay. Insets in $\mathbf{a}$ and $\mathbf{b}$ indicate number of clones above or below $\mathrm{Y}$ axis limits (set to 2 and -2 for visualization) 
bioRxiv preprint doi: https://doi.org/10.1101/494062; this version posted February 5, 2020. The copyright holder for this preprint (which was not certified by peer review) is the author/funder, who has granted bioRxiv a license to display the preprint in perpetuity. It is made available under aCC-BY-NC-ND 4.0 International license.

a

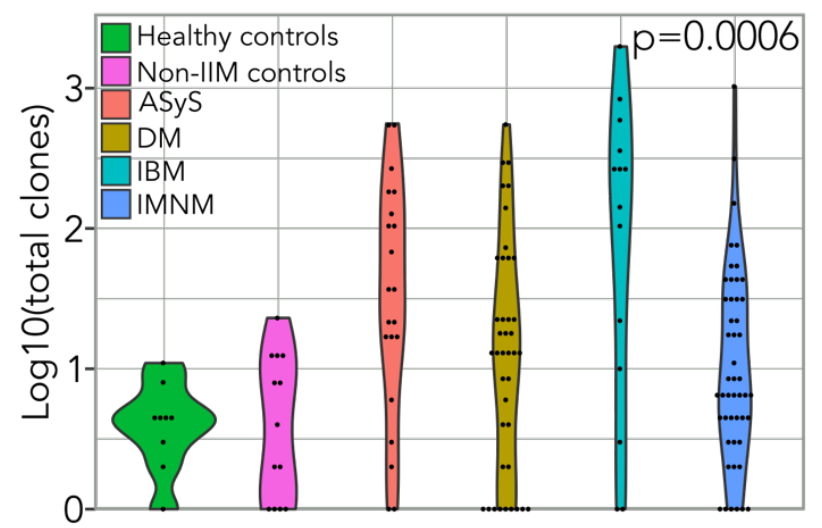

b

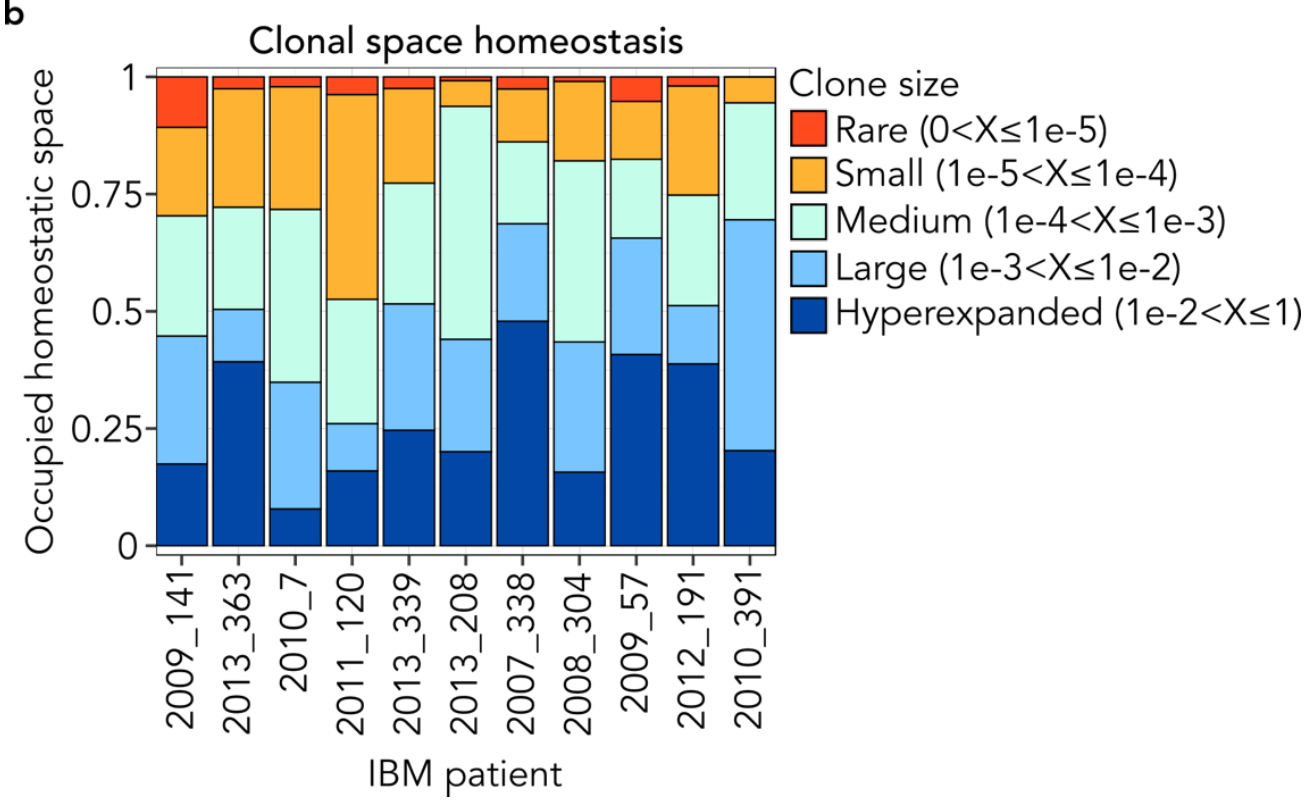

Figure S5: a. Distributions of unique clones per patient for each IIM subgroup and controls. Kruskal-Wallis

598 p-value is shown. b. Clonal space homeostasis for each IBM donor with at least one clone present at >2 T cell equivalents in their muscle biopsy. Criteria for clone size are shown. 
bioRxiv preprint doi: https://doi.org/10.1101/494062; this version posted February 5, 2020. The copyright holder for this preprint (which was not certified by peer review) is the author/funder, who has granted bioRxiv a license to display the preprint in perpetuity. It is made available under aCC-BY-NC-ND 4.0 International license.

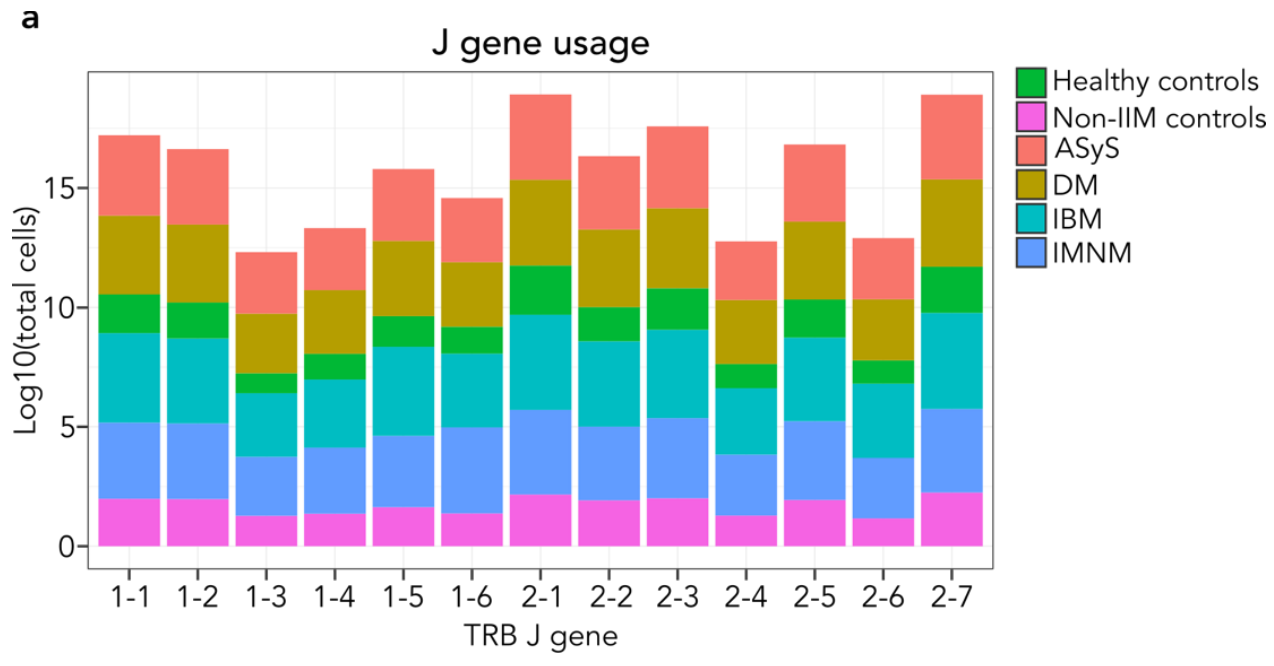

b

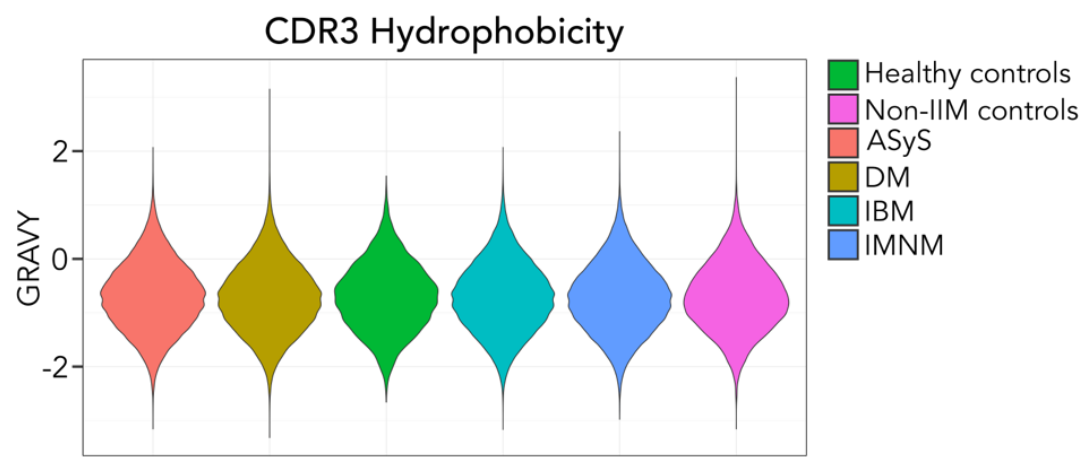

C

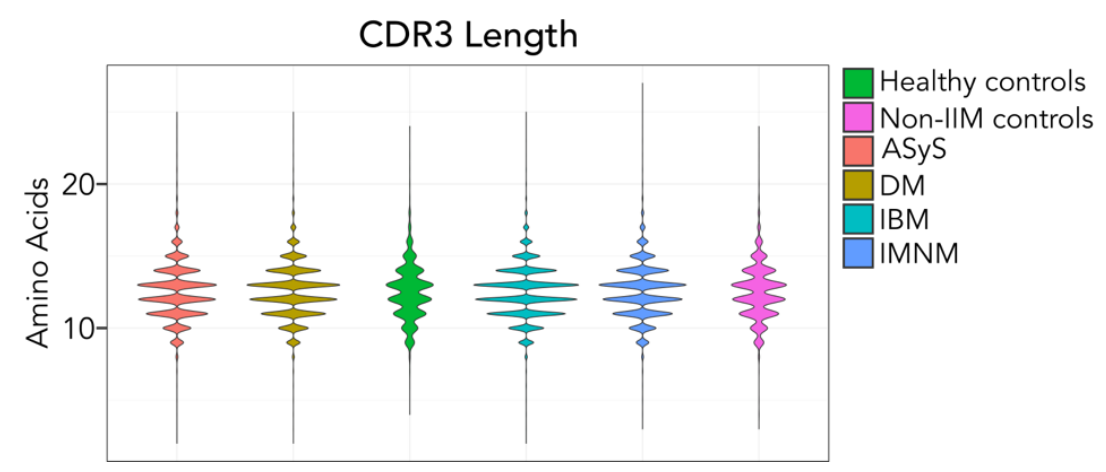

601 Figure S6: Summary statistics of FR3AK-seq TCRB repertoires from each IIM subgroup and controls. a.

602 Stacked bar plot of $\mathrm{J}$ gene usage for each IIM subgroup and controls. b. Grand Average of Hydropathy

603 (GRAVY) for CDR3s from each IIM subgroup and controls. c. CDR3 length comparisons between each IIM

604 subgroup and controls. 


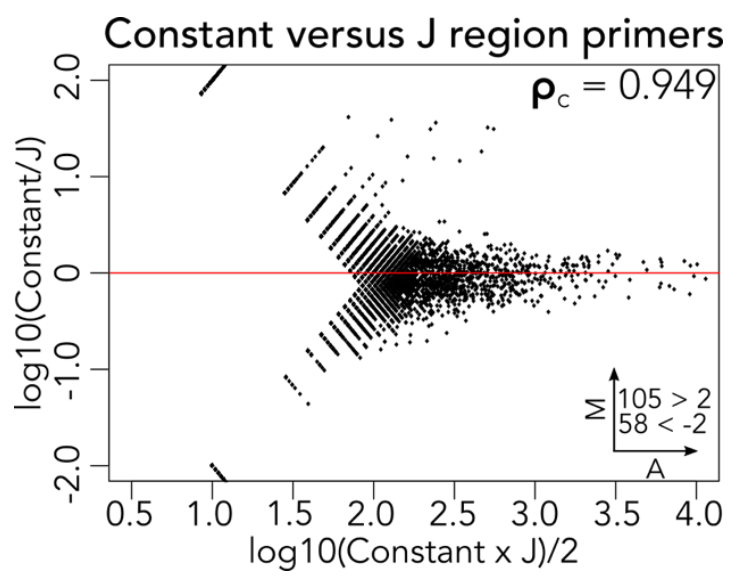

Figure S7: MA plot demonstrating the performance of the FR3AK-seq constant region reverse PCR1 primer as compared to a set of $\mathrm{J}$ region reverse primers. cDNA was used as a starting material along with the 1MM forward primer set with PCR conditions as described in the Methods section. CDR3 sequences were in Table S8.

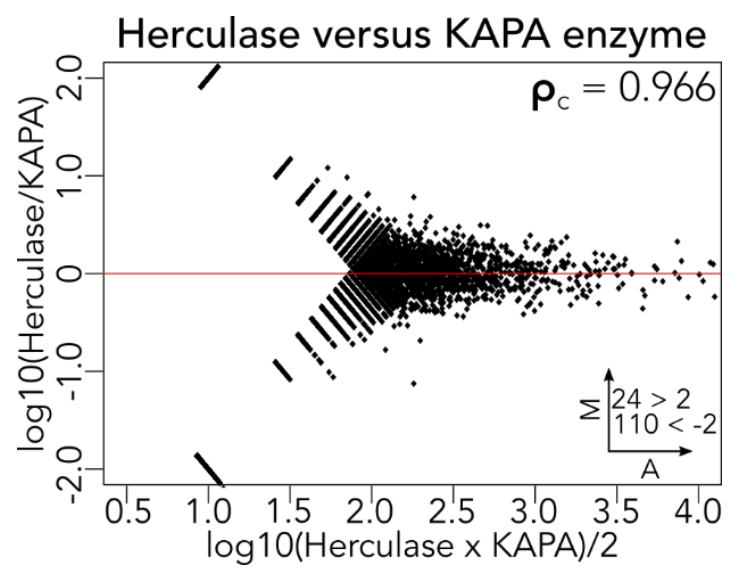

612 Figure S8: MA plot demonstrates that Herculase II Fusion DNA polymerase performs comparably to KAPA 613 2G Fast Multiplex Mix in PCR1. CDR3 sequences were included in this analysis if they had a clone count 614 of $\geq 10$ in either data set. 
SUPPLEMENTARY TABLES:

\begin{tabular}{|c|c|c|c|}
\hline \multicolumn{4}{|c|}{ Table S1: FR3AK-seq human TCRB primers } \\
\hline \multicolumn{4}{|c|}{ TCRB constant region primers } \\
\hline \multicolumn{2}{|c|}{ Sequence } & \multicolumn{2}{|l|}{ Step } \\
\hline \multicolumn{2}{|c|}{ accagtgtggccttttgggtgtg } & \multicolumn{2}{|c|}{ Reverse transcription } \\
\hline \multicolumn{2}{|c|}{ cttttgggtgtgggagatctctg } & \multicolumn{2}{|c|}{ Reverse primer: PCRI } \\
\hline \multicolumn{4}{|c|}{ Adapter sequence for TCRB constant region PCRI primer (add to 5' end) } \\
\hline \multicolumn{2}{|c|}{ Sequence } & \multicolumn{2}{|c|}{ Adapter name } \\
\hline ctggagttcagacgtgtgctc & atct & & \\
\hline \multicolumn{4}{|c|}{ Adapter sequence for FR3 primers (add to 5' end) } \\
\hline \multicolumn{2}{|c|}{ Sequence } & \multicolumn{2}{|c|}{ Adapter name } \\
\hline ggagctgtcgttcactc & & & \\
\hline \multicolumn{4}{|c|}{ Full: TCRB FR3 primers } \\
\hline Primer Sequence & $\begin{array}{l}\text { IMGT Accession | } \\
\text { Associated V allele }\end{array}$ & $\begin{array}{l}\text { Unique } \\
\text { FR3 \& } \\
\text { Heatmap } \\
\text { order }\end{array}$ & $\begin{array}{l}\text { Gel } \\
\text { order }\end{array}$ \\
\hline actccgccgtgtatctctgt & $\begin{array}{l}\text { X61441|TRBV7-8*02 } \\
\text { M11953|TRBV7-8*01 } \\
\text { M27384|TRBV7-8*03 }\end{array}$ & 1 & 25 \\
\hline actctgccgtgtatctctgt & X74843|TRBV7-3*04 & 2 & 20 \\
\hline actcggccgtgtatctctgt & $\begin{array}{l}\text { X58797|TRBV11-3*02 } \\
\text { X61442|TRBV7-2*01 } \\
\text { L36190|TRBV7-2*02 } \\
\text { X58796|TRBV11-2*03 } \\
\text { M27387|TRBV7-2*04 } \\
\text { U03115|TRBV11-3*01 } \\
\text { L36092|TRBV11-2*01 } \\
\text { U07975|TRBV7-2*03 } \\
\text { M33235|TRBV11-2*02 } \\
\text { MGT000021|TRBV11-2*04 } \\
\text { AB305924|TRBV11-3*04 }\end{array}$ & 3 & 47 \\
\hline actcagccgtgtatctctgt & $\begin{array}{l}\text { M13550|TRBV7-3*05 } \\
\text { X61440|TRBV7-3*01 }\end{array}$ & 4 & 4 \\
\hline actcagctgtgtatctctgt & L36092|TRBV7-4*01 & 5 & 36 \\
\hline actcagccgtgtatctccgt & M97943|TRBV7-3*02 & 6 & 45 \\
\hline actcagccgcgtatctccgt & AF009660|TRBV7-3*03 & 7 & 15 \\
\hline actcggccatgtatcgctgt & $\begin{array}{l}\text { X58806|TRBV7-6*02 } \\
\text { L36092|TRBV7-6*01 }\end{array}$ & 8 & 23 \\
\hline actcagccatgtatcgctgt & $\begin{array}{l}\text { L36092|TRBV7-7*01 } \\
\text { X57607|TRBV7-7*02 }\end{array}$ & 9 & 37 \\
\hline actcggccatgtatctctgt & $\begin{array}{l}\text { M33233|TRBV11-1*01 } \\
\text { L14854|TRBV7-9*07 } \\
\text { M27385|TRBV7-9*05 } \\
\text { M14261|TRBV7-9*04 } \\
\text { AF009663|TRBV7-9*03 } \\
\text { M62377|TRBV11-3*03 } \\
\text { L36092|TRBV7-9*01 }\end{array}$ & 10 & 26 \\
\hline
\end{tabular}




\begin{tabular}{|c|c|c|c|}
\hline & $\begin{array}{l}\text { M15564|TRBV7-9*02 } \\
\text { X74844|TRBV7-9*06 }\end{array}$ & & \\
\hline actcagccgtgtatctctac & $\begin{array}{l}\text { U03115|TRBV17*01 } \\
\text { IMGT000021|TRBV17*02 }\end{array}$ & 11 & 34 \\
\hline actcagccetgtatctctgc & $\begin{array}{l}\text { U07977|TRBV4-1*01 } \\
\text { M13855|TRBV4-1*02 }\end{array}$ & 12 & 5 \\
\hline acttggctgtgtatctctgt & X61444|TRBV7-1*01 & 13 & 33 \\
\hline actcggccetgtatctctgc & $\begin{array}{l}\text { X58812|TRBV4-3*02 } \\
\text { L06888|TRBV4-3*03 } \\
\text { X57616|TRBV4-3*04 } \\
\text { U07978|TRBV4-3*01 }\end{array}$ & 14 & 27 \\
\hline actcggccetgtatctctgt & $\begin{array}{l}\text { X58811|TRBV4-2*02 } \\
\text { U07975|TRBV4-2*01 } \\
\text { X57611|TRBV5-5*02 } \\
\text { X57615|TRBV5-4*02 } \\
\text { X58803|TRBV5-8*02 } \\
\text { L36092|TRBV5-8*01 } \\
\text { X58804|TRBV5-4*04 } \\
\text { L36092|TRBV5-5*01 } \\
\text { L36092|TRBV5-4*01 } \\
\text { AF009660|TRBV5-3*02 } \\
\text { X58801|TRBV5-5*03 } \\
\text { S50547|TRBV5-4*03 } \\
\text { X61439|TRBV5-3*01 }\end{array}$ & 15 & 1 \\
\hline actcggccetctatctctgt & $\begin{array}{l}\text { L36092|TRBV5-6*01 } \\
\text { L36092|TRBV5-7*01 }\end{array}$ & 16 & 18 \\
\hline actcggccetttatctttgc & $\begin{array}{l}\text { L36092|TRBV5-1*01 } \\
\text { M14271|TRBV5-1*02 }\end{array}$ & 17 & 40 \\
\hline acacggcactgtatctctgc & L36092|TRBV23-1*01 & 18 & 39 \\
\hline actcagctgtgtacttctgt & $\begin{array}{l}\text { K02546|TRBV12-4*01 } \\
\text { X07192|TRBV12-3*01 } \\
\text { M14264|TRBV12-4*02 }\end{array}$ & 19 & 31 \\
\hline actcagctgtgtatttttgt & X07223|TRBV12-5*01 & 20 & 14 \\
\hline actcagctttgtatttctgt & $\begin{array}{l}\text { L36092|TRBV9*01 } \\
\text { M27380|TRBV9*03 } \\
\text { AF009660|TRBV9*02 }\end{array}$ & 21 & 19 \\
\hline actctgctgtgtatttctgt & $\begin{array}{l}\text { L06889|TRBV3-1*02 } \\
\text { U07977|TRBV3-1*01 }\end{array}$ & 22 & 28 \\
\hline actcagccatgtacttctgt & $\begin{array}{l}\text { M64351|TRBV2*03 } \\
\text { L36092|TRBV2*01 } \\
\text { M62379|TRBV2*02 }\end{array}$ & 23 & 44 \\
\hline actcagccetgtacttctgt & $\begin{array}{l}\text { U03115|TRBV13*01 } \\
\text { M62378|TRBV13*02 }\end{array}$ & 24 & 9 \\
\hline actctggcttctatctctgt & $\begin{array}{l}\text { L36092|TRBV30*01 } \\
\text { M13554|TRBV30*04 } \\
\text { L06893|TRBV30*05 } \\
\text { Z13967|TRBV30*02 }\end{array}$ & 25 & 22 \\
\hline acgcagccatgtacctgtgt & $\begin{array}{l}\text { X58800|TRBV15*02 } \\
\text { IMGT000021|TRBV15*04 }\end{array}$ & 26 & 43 \\
\hline acacagccatgtacctgtgt & U03115|TRBV15*01 & 27 & 3 \\
\hline
\end{tabular}




\begin{tabular}{|c|c|c|c|}
\hline acgcagccatgtaccagtgt & M62376|TRBV15*03 & 28 & 42 \\
\hline attcggcagcttatttctgt & L36092|TRBV18*01 & 29 & 16 \\
\hline attctggagtttatttctgt & $\begin{array}{l}\text { X57722|TRBV14*02 } \\
\text { X06154|TRBV14*01 }\end{array}$ & 30 & 46 \\
\hline attcagcagtgtatttttgt & $\begin{array}{l}\text { L26054|TRBV16*03 } \\
\text { L26231|TRBV16*01 }\end{array}$ & 31 & 7 \\
\hline agacatctgtgtacttctgt & $\begin{array}{l}\text { AF009662|TRBV6-6*02 } \\
\text { X58815|TRBV6-6*03 } \\
\text { L33102|TRBV10-3*04 } \\
\text { L36092|TRBV6-6*01 } \\
\text { U17047|TRBV10-3*02 } \\
\text { U03115|TRBV10-3*01 } \\
\text { AF009660|TRBV6-4*02 } \\
\text { X61446|TRBV6-1*01 } \\
\text { L06892|TRBV6-6*05 } \\
\text { X74848|TRBV6-6*04 } \\
\text { L33101|TRBV10-3*03 } \\
\text { X61653|TRBV6-4*01 } \\
\text { L36092|TRBV6-5*01 }\end{array}$ & 32 & 29 \\
\hline agacatctgtgtacttgtgt & L36092|TRBV6-8*01 & 33 & 21 \\
\hline aacatctgtgtacttctgt & $\begin{array}{l}\text { U07978|TRBV6-3*01 } \\
\text { X61445|TRBV6-2*01 }\end{array}$ & 34 & 24 \\
\hline agacatctgtatacttctgt & X61447|TRBV6-9*01 & 35 & 30 \\
\hline agacttctgtttacttctgt & L36092|TRBV6-7*01 & 36 & 10 \\
\hline agacctctctgtacttctgt & L36092|TRBV27*01 & 37 & 6 \\
\hline agacatctatgtacctctgt & U08314|TRBV28*01 & 38 & 38 \\
\hline agacagctctttacttctgt & $\begin{array}{l}\text { M11951|TRBV24-1*01 } \\
\text { IMGT000021|TRBV24-1*02 }\end{array}$ & 39 & 8 \\
\hline agacatctgtatatttctgc & $\begin{array}{l}\text { L36092|TRBV10-1*01 } \\
\text { AF009660|TRBV10-1*02 }\end{array}$ & 40 & 35 \\
\hline agacatctgtgtatttctgc & $\begin{array}{l}\text { L36092|TRBV10-2*01 } \\
\text { IMGT000021|TRBV10-2*03 }\end{array}$ & 41 & 32 \\
\hline atacctctcagtacctctgt & L36092|TRBV25-1*01 & 42 & 41 \\
\hline cgacagctttctatctctgt & $\begin{array}{l}\text { U48259|TRBV19*02 } \\
\text { M97725|TRBV19*03 } \\
\text { L36092|TRBV19*01 }\end{array}$ & 43 & 2 \\
\hline gcttctacatctgcagtgct & X72719|TRBV20-1*02 & 44 & 17 \\
\hline acagcagcttctacatctgc & $\begin{array}{l}\text { D13088|TRBV20-1*06 } \\
\text { X57604|TRBV20-1*05 } \\
\text { M14263|TRBV20-1*04 } \\
\text { M11955|TRBV20-1*01 } \\
\text { X74852|TRBV20-1*07 } \\
\text { M11954|TRBV20-1*03 }\end{array}$ & 45 & 12 \\
\hline acagcagcatatatctctgc & $\begin{array}{l}\text { L36092|TRBV29-1*01 } \\
\text { X04926|TRBV29-1*03 } \\
\text { M13847|TRBV29-1*02 }\end{array}$ & 46 & 13 \\
\hline cccgctcccagacatctgtg & U17048|TRBV10-2*02 & 47 & 11 \\
\hline
\end{tabular}


bioRxiv preprint doi: https://doi.org/10.1101/494062; this version posted February 5, 2020. The copyright holder for this preprint (which was not certified by peer review) is the author/funder, who has granted bioRxiv a license to display the preprint in perpetuity. It is made available under aCC-BY-NC-ND 4.0 International license.

\begin{tabular}{|c|c|c|}
\hline Primer Sequence & $\begin{array}{c}\text { Heatmap } \\
\text { Order }\end{array}$ & $\begin{array}{c}\text { Gel } \\
\text { Order }\end{array}$ \\
\hline actcggccgtgtatctctgt & 1 & 25 \\
\hline actcagctgtgtatctctgt & 2 & 19 \\
\hline actcagccgcgtatctccgt & 3 & 9 \\
\hline actcagccatgtatcgctgt & 4 & 20 \\
\hline actcagccgtgtatctctac & 5 & 26 \\
\hline actcagccetgtatctctgc & 6 & 1 \\
\hline acttggctgtgtatctctgt & 7 & 18 \\
\hline actcggccetctatctctgt & 8 & 11 \\
\hline actcggccetttatctttgc & 9 & 22 \\
\hline acacggcactgtatctctgc & 10 & 30 \\
\hline actcagctgtgtacttctgt & 11 & 16 \\
\hline actcagctgtgtatttttgt & 12 & 28 \\
\hline actcagctttgtatttctgt & 13 & 12 \\
\hline actctgctgtgtatttctgt & 14 & 14 \\
\hline actcagccetgtacttctgt & 15 & 5 \\
\hline actctggcttctatctctgt & 16 & 27 \\
\hline acgcagccatgtacctgtgt & 17 & 24 \\
\hline acgcagccatgtaccagtgt & 18 & 23 \\
\hline attcggcagcttatttctgt & 19 & 10 \\
\hline attctggagtttatttctgt & 20 & 29 \\
\hline attcagcagtgtatttttgt & 21 & 3 \\
\hline agacatctgtgtacttctgt & 22 & 15 \\
\hline agacatctgtgtacttgtgt & 23 & 13 \\
\hline agacttctgtttacttctgt & 24 & 6 \\
\hline agacctctctgtacttctgt & 25 & 2 \\
\hline agacatctatgtacctctgt & 26 & 21 \\
\hline agacagctctttacttctgt & 27 & 4 \\
\hline agacatctgtgtatttctgc & 28 & 17 \\
\hline atacctctcagtacctctgt & 29 & 34 \\
\hline cgacagctttctatctctgt & 30 & 33 \\
\hline gcttctacatctgcagtgct & 31 & 31 \\
\hline acagcagcttctacatctgc & 32 & 7 \\
\hline acagcagcatatatctctgc & 33 & 8 \\
\hline cccgctcccagacatctgtg & 34 & 32 \\
\hline \multicolumn{3}{|c|}{ Compact: TCRB FR3 primers } \\
\hline Primer Sequence & $\begin{array}{c}\text { Heatmap } \\
\text { Order }\end{array}$ & $\begin{array}{c}\text { Gel } \\
\text { Order }\end{array}$ \\
\hline actcigciitgtatctctgt & 1 & 1 \\
\hline actcagccgigtatctccgt & 2 & 7 \\
\hline actcggccatgtatcgctgt & 3 & 11 \\
\hline actcagccgtgtatctctac & 4 & 10 \\
\hline actcigccetitatctitgc & 5 & 5 \\
\hline acacggcactgtatctctgc & 6 & 16 \\
\hline actcagctgtgtatttttgt & 7 & 14 \\
\hline actctggcttctatctctgt & 8 & 12 \\
\hline acicagccatgtacciitgt & 9 & 4 \\
\hline attcggcagiitatttitgt & 10 & 8 \\
\hline
\end{tabular}




\begin{tabular}{|c|c|c|}
\hline attctggagtttatttctgt & 11 & 15 \\
\hline agacatctitgtacititgt & 12 & 3 \\
\hline agaciictitttacttctgt & 13 & 13 \\
\hline actcagciitgtacttctgt & 14 & 2 \\
\hline agacatctgtitatttctgc & 15 & 6 \\
\hline atacctctcagtacctctgt & 16 & 20 \\
\hline cgacagctttctatctctgt & 17 & 19 \\
\hline gcttctacatctgcagtgct & 18 & 17 \\
\hline acagcagcttitaitctgc & 19 & 9 \\
\hline cccgctcccagacatctgtg & 20 & 18 \\
\hline \multicolumn{3}{|l|}{ PCR2 primers } \\
\hline Primer Sequence: $\mathrm{X}$ refers to barcode nucleotides & \multicolumn{2}{|c|}{ Adapters } \\
\hline $\begin{array}{l}\text { caagcagaagacggcatacgagatXXXXXXXXgtgactggagttcagacgtg } \\
\text { tgctcttccgatct }\end{array}$ & \multicolumn{2}{|c|}{ P7_ad_min } \\
\hline $\begin{array}{l}\text { aatgatacggcgaccaccgagatctacacXXXXXXXXacactctttccgatc } \\
\text { tggagctgtcgttcactc }\end{array}$ & \multicolumn{2}{|c|}{ P5_AD1.2 } \\
\hline
\end{tabular}

Table S1: Human TCRB FR3AK-seq primers and adapter sequences.

\begin{tabular}{|c|c|c|c|}
\hline \multicolumn{4}{|c|}{ Table S2: FR3AK-seq cost per sample } \\
\hline Step & Item & Price & Cost per sample \\
\hline $\begin{array}{l}\text { Reverse } \\
\text { Transcription }\end{array}$ & $\begin{array}{l}\text { Invitrogen Superscript } \\
\text { III first-strand synthesis } \\
\text { system }\end{array}$ & $\begin{array}{l}\$ 467.00 \\
\text { (50 reactions) }\end{array}$ & $\$ 9.34$ \\
\hline cDNA clean up & $\begin{array}{l}\text { Zymo Research Oligo } \\
\text { Clean \& Concentrator }\end{array}$ & $\begin{array}{l}423.00 \\
\text { (384 preps) }\end{array}$ & $\$ 1.10$ \\
\hline PCR1 & $\begin{array}{l}\text { KAPA2G Fast Multiplex } \\
\text { Mix }\end{array}$ & $\begin{array}{l}\$ 295.88 \\
(6.25 \mathrm{~mL} / \\
624-20 \mu \mathrm{L} \text { reactions })\end{array}$ & $\$ 0.47$ \\
\hline PCR2 & $\begin{array}{l}\text { Herculase II Fusion } \\
\text { DNA Polymerase }\end{array}$ & $\begin{array}{l}\$ 475.00 \\
(400 \mathrm{uL}, \\
2000-20 \text { uL reactions) }\end{array}$ & $\$ 0.24$ \\
\hline $\begin{array}{l}\text { Reverse } \\
\text { Transcription, 1MM } \\
\text { PCR1, PCR2 }\end{array}$ & Primers & $\begin{array}{l}\$ 204.75 \text { (36 primers, } \\
6250 \text { reactions } \\
\text { PCR1/RT) } \\
\$ 11.38 \text { ( } 2 \text { primers, } 5000 \\
\text { reactions PCR2) }\end{array}$ & $\begin{array}{l}\$ 0.03 \\
\$ 0.002\end{array}$ \\
\hline Plastics & Pipet tips, tubes, etc. & \$1.00/sample & $\$ 1.00$ \\
\hline $\begin{array}{l}\text { Sequencing (HiSeq } \\
\text { 2500) }\end{array}$ & $\begin{array}{l}100 \text { nt single-end } \\
\text { Illumina reads, } 213 \\
\text { samples at } \sim 1 \times 10^{6} \\
\text { reads per sample }\end{array}$ & $\begin{array}{l}\$ 1600.00 \\
\text { (100bp, per lane) }\end{array}$ & $\$ 7.51$ \\
\hline & TOTAL & & $\$ 19.69$ \\
\hline
\end{tabular}

Table S2: Cost per sample for FR3AK-seq. HiSeq cost calculations were based on the Johns Hopkins 

spent by the researcher.

\section{Table S3: Idiopathic Inflammatory Myopathy and Control Muscle Biopsy Cohort}

\begin{tabular}{|l|l|l|l|l|l|l|}
\hline \multicolumn{5}{|c|}{ Table S3: Idiopathic Inflammatory Myopathy and Control Muscle Biopsy Cohort } \\
\hline & $\begin{array}{l}\text { Controls } \\
(n=21)\end{array}$ & $\begin{array}{l}\text { DM } \\
(n=40)\end{array}$ & $\begin{array}{l}\text { ASyS } \\
(n=21)\end{array}$ & $\begin{array}{l}\text { IMNM } \\
(n=49)\end{array}$ & $\begin{array}{l}\text { IBM } \\
(n=14)\end{array}$ & $\begin{array}{l}\text { Total } \\
(n=145)\end{array}$ \\
\hline Female & $71 \%(15)$ & $53 \%(9)$ & $89 \%(8)$ & $67 \%(18)$ & $54 \%(7)$ & $66 \%(57)$ \\
\hline White & $82 \%(9)$ & $71 \%(12)$ & $44 \%(4)$ & $56 \%(15)$ & $83 \%(10)$ & $66 \%(50)$ \\
\hline Black & $18 \%(2)$ & $18 \%(3)$ & $44 \%(4)$ & $37 \%(10)$ & $17 \%(2)$ & $28 \%(21)$ \\
\hline Other race & $0 \%(0)$ & $12 \%(2)$ & $11 \%(1)$ & $7 \%(2)$ & $0 \%(0)$ & $7 \%(5)$ \\
\hline Age & $50.6(13.9)$ & $59.7(13.4)$ & $46.2(8.4)$ & $51.8(13.4)$ & $66.1(11.6)^{* *}$ & $54.6(14.0)$ \\
\hline
\end{tabular}

${ }^{*} p<0.05,{ }^{* *} p<0.01,{ }^{* * *} p<0.001$

Table S3: Description of the IIM muscle biopsy cohort. Chi-squared or Fisher's exact tests were used to compare the dichotomous variables of each one of the clinical groups with the rest. Student's T test was Input IIM FR3AK-seq data

\begin{tabular}{|l|l|}
\hline $\begin{array}{l}\text { Number of samples with non-bystander T cell } \\
\text { clones }\end{array}$ & 122 (23 excluded) \\
\hline $\begin{array}{l}\text { Number of non-bystander T cell clones included in } \\
\text { analysis }\end{array}$ & 11351 \\
\hline Number of bystander T cell clones & 278121 \\
\hline \multicolumn{2}{|c|}{ GLIPH Output } \\
\hline Total number of GLIPH clusters & 527 \\
\hline $\begin{array}{l}\text { Total number of GLIPH clusters with at least 3 } \\
\text { individuals contributing a T cell clone }\end{array}$ & 143 \\
\hline $\begin{array}{l}\text { Number of non-bystander T cell clones clustered by } \\
\text { GLIPH }\end{array}$ & 2125 \\
\hline
\end{tabular}




\begin{tabular}{|c|c|c|c|c|c|c|c|}
\hline \multicolumn{8}{|c|}{ Table S5: Comparisons between platforms } \\
\hline Platform & \multicolumn{2}{|c|}{$\begin{array}{c}\text { ImmunoSEQ } \\
\text { hsTCRB service } \\
\text { (Adaptive } \\
\text { Biotechnologies) } \\
\end{array}$} & \multicolumn{2}{|c|}{$\begin{array}{c}\text { ImmunoSEQ } \\
\text { hsTCRB kit } \\
\text { (Adaptive } \\
\text { Biotechnologies) }\end{array}$} & \multicolumn{2}{|c|}{$\begin{array}{l}\text { Immunoverse } \\
\text { (ArcherDX) }\end{array}$} & FR3AK-seq \\
\hline Method & \multicolumn{2}{|c|}{$\begin{array}{l}\text { Multiplex PCR with } \\
\text { bias correction }\end{array}$} & \multicolumn{2}{|c|}{$\begin{array}{l}\text { Multiplex PCR with } \\
\text { bias correction }\end{array}$} & \multicolumn{2}{|l|}{ UMI } & Multiplex PCR \\
\hline Time & \multicolumn{2}{|c|}{$\begin{array}{l}\text { - } \quad<1 \text { day to prepare } \\
\text { sample and ship } \\
\text { to company } \\
\text { - Processed data } \\
\text { within } \sim 2-3 \text { weeks }\end{array}$} & \multicolumn{2}{|c|}{$\begin{array}{ll}\text { - } & <1 \text { day to } \\
\text { prepare } \\
\text { sample } \\
-1 \text { day to } \\
\text { obtain } \\
\text { processed } \\
\text { data }\end{array}$} & \multicolumn{2}{|c|}{$\begin{array}{ll} & \sim 2 \text { days for } \\
\text { library } \\
\text { preparation } \\
\text { - } \quad \text { day to } \\
\text { obtain } \\
\text { processed } \\
\text { data } \\
\end{array}$} & $\begin{array}{ll}\text { - } & \sim 1 \text { day for } \\
& \text { library } \\
\text { preparation } \\
\text { - } & \sim 1 \text { day to } \\
\text { obtain } \\
\text { processed } \\
\text { data }\end{array}$ \\
\hline $\begin{array}{l}\text { Hands- } \\
\text { on user } \\
\text { steps }\end{array}$ & \multicolumn{2}{|c|}{$\begin{array}{ll}- & \text { Reverse } \\
\text { transcription (if } \\
\text { using cDNA) }\end{array}$} & \multicolumn{2}{|c|}{$\begin{array}{ll}\text { - } & 3 \text { step library } \\
& \text { preparation (if } \\
& \text { using cDNA) } \\
\text { - } & \text { Sequencing } \\
\text { - } & \text { Upload fasta } \\
& \text { files to } \\
\text { immunoSEQ } \\
\text { analyzer for } \\
\text { bias correction }\end{array}$} & \multicolumn{2}{|c|}{$\begin{array}{ll}\text { - } & 9 \text { step library } \\
\text { preparation } \\
\text { - } & \text { Sequencing } \\
\text { - } & \text { Upload fastq } \\
\text { files to } \\
\text { ArcherDX } \\
\text { portal for } \\
\text { deduplication } \\
\text { analysis }\end{array}$} & $\begin{array}{ll}\text { - } & 3 \text { step } \\
& \text { library } \\
& \text { preparation } \\
\text { - } & \text { Sequencing } \\
\text { - } & \text { MiXCR } \\
& \text { analysis }\end{array}$ \\
\hline \multirow[t]{3}{*}{$\begin{array}{l}\text { Cost per } \\
\text { sample }\end{array}$} & $\begin{array}{l}\text { Reverse } \\
\text { transcription }\end{array}$ & $\$ 9.87$ & Kit & $\$ 629.00$ & Kit & $\$ 240.00$ & \multirow[t]{2}{*}{$\begin{array}{l}\$ 19.69 \text { (see } \\
\text { Table S2) }\end{array}$} \\
\hline & $\begin{array}{l}\text { Deep } \\
\text { Sequencing } \\
\text { Service }\end{array}$ & $\$ 1100$ & MiSeq & $\$ 44.00$ & MiSeq & $\$ 44.00$ & \\
\hline & \multicolumn{2}{|c|}{ TOTAL: $\$ 1109.87$} & \multicolumn{2}{|c|}{ TOTAL: $\$ 642.02$} & \multicolumn{2}{|c|}{ TOTAL: $\$ 284.00$} & TOTAL: $\$ 19.69$ \\
\hline
\end{tabular}

Table S5: Comparisons between Adaptive Biotechnologies' immunoSEQ assay (both service and kit),

\begin{tabular}{|c|c|c|}
\hline \multicolumn{3}{|c|}{ Table S6: FR3AK-seq Mus musculus TCRB primers } \\
\hline \multicolumn{3}{|c|}{ Mus musculus TCRB constant region primers } \\
\hline \multicolumn{2}{|c|}{ Sequence } & Step \\
\hline \multicolumn{2}{|l|}{ tggctcaaacaaggagaccttgg } & Reverse transcription \\
\hline \multicolumn{2}{|l|}{ ggtggagtcacatttctcagatcc } & Reverse primer: PCRI \\
\hline \multicolumn{3}{|c|}{ Full: Mus musculus TCRB FR3 primers } \\
\hline Primer Sequence & \multicolumn{2}{|c|}{$\begin{array}{l}\text { IMGT Accession | } \\
\text { Associated V allele }\end{array}$} \\
\hline acagcagtatctatttctgt & \multicolumn{2}{|l|}{ X16695|TRBV30*01 } \\
\hline agatgaccgtttttctctgt & \multicolumn{2}{|l|}{ X01643|TRBV19*02 } \\
\hline actctgctgtgtatctctgt & \multicolumn{2}{|l|}{ AJ249819|TRBV4*02 } \\
\hline
\end{tabular}




\begin{tabular}{|c|c|}
\hline & X56725|TRBV4*01 \\
\hline agacatctttgtacttctgt & $\begin{array}{l}\text { AE000663|TRBV13-1*02 } \\
\text { M15618|TRBV13-1*01 }\end{array}$ \\
\hline aaggcagaaccttgtactgc & X01642|TRBV1*02 \\
\hline agatggccgtttttctctgt & $\begin{array}{l}\text { AE000664|TRBV19*01 } \\
\text { AJ249821|TRBV19*03 }\end{array}$ \\
\hline actctggcttctacctctgt & $\begin{array}{l}\text { X03277|TRBV31*01 } \\
\text { M26418|TRBV31*02 }\end{array}$ \\
\hline actcagctgtctatttttgt & $\begin{array}{l}\text { AJ249820|TRBV5*05 } \\
\text { M20878|TRBV5*04 } \\
\text { X00438|TRBV5*02 } \\
\text { X02779|TRBV5 } 03 \\
\text { AE000663|TRBV5*01 }\end{array}$ \\
\hline acagaggcttatatctctgt & $\begin{array}{l}\text { AE000664|TRBV20*01 } \\
\text { M11859|TRBV20*02 }\end{array}$ \\
\hline attcagctgtgtacttctgt & X16691|TRBV21*01 \\
\hline actcagcggtgtatctttgt & $\begin{array}{l}\text { X14388|TRBV16*04 } \\
\text { M15459|TRBV16*03 } \\
\text { M13670|TRBV16*02 } \\
\text { L29434|TRBV16*01 }\end{array}$ \\
\hline actcagcactgtacttgtgc & AE000664|TRBV23*01 \\
\hline agggcagaaccttgtactgc & AE000663|TRBV1*01 \\
\hline agacagctgtatatttctgt & M15616|TRBV13-3*01 \\
\hline actcagctgtgtacttctgt & $\begin{array}{l}\text { X03865|TRBV3*02 } \\
\text { AE000663|TRBV3*01 }\end{array}$ \\
\hline actcagcactgtacctctgt & $\begin{array}{l}\text { L48997|TRBV24*04 } \\
\text { M16203|TRBV24*03 } \\
\text { AJ249822|TRBV26*02 } \\
\text { K02548|TRBV26*01 } \\
\text { M61184|TRBV24*01 }\end{array}$ \\
\hline actcagctgtgtatctgtgt & AE000664|TRBV15*01 \\
\hline agacatcagtgtacttctgt & $\begin{array}{l}\text { AJ250103|TRBV13-2*05 } \\
\text { M26417|TRBV13-2*03 } \\
\text { AJ249823|TRBV13-2*04 } \\
\text { M15617|TRBV13-2*01 } \\
\text { M27350|TRBV13-2*02 }\end{array}$ \\
\hline attctgccatgtacctctgt & AE000664|TRBV17*01 \\
\hline agacatctgtgtacttctgt & $\begin{array}{l}\text { X00696|TRBV29*02 } \\
\text { AE000664|TRBV29*01 }\end{array}$ \\
\hline actcggccacatacttctgt & AE000663|TRBV2*01 \\
\hline actctgccgtgtacttctgt & $\begin{array}{l}\text { M15613|TRBV12-2*01 } \\
\text { X02782|TRBV12-2*02 }\end{array}$ \\
\hline actctgctatgtacttctgt & $\begin{array}{l}\text { M30881|TRBV12-1*02 } \\
\text { M15614|TRBV12-1*01 }\end{array}$ \\
\hline acacagccacctatctctgt & AE000664|TRBV14*01 \\
\hline
\end{tabular}




\begin{tabular}{|c|c|}
\hline \multicolumn{2}{|c|}{$\begin{array}{c}\text { Table S7: FR3AK-seq human TCRA, TCRG, and TCRD primers } \\
\text { human TCRA: constant region primers }\end{array}$} \\
\hline \multicolumn{2}{|c|}{ Sequence } \\
\hline \multicolumn{2}{|l|}{ cggtgaataggcagacagacttg } \\
\hline cagacttgtcactggatttagag & Reverse primer: PCRI \\
\hline \multicolumn{2}{|c|}{ Full: human TCRA FR3 primers } \\
\hline Primer Sequence & $\begin{array}{l}\text { IMGT Accession | } \\
\text { Associated V allele }\end{array}$ \\
\hline atgctgctgtgtactactgc & AE000660|TRAV26-2*01 \\
\hline actcagccacctacttctgt & $\begin{array}{l}\text { M17660|TRAV23/DV6*02 } \\
\text { AE000660|TRAV23/DV6*01 } \\
\text { M97704|TRAV23/DV6*03 }\end{array}$ \\
\hline actcagctatctacttctgt & AE000659|TRAV5*01 \\
\hline atgctgctgagtacttctgt & $\begin{array}{l}\text { AE000659|TRAV8-3*01 } \\
\text { AE000660|TRAV8-7*01 } \\
\text { M35617|TRAV8-3*02 }\end{array}$ \\
\hline atgcgtctgagtacttctgt & L06885|TRAV8-3*03 \\
\hline atacaggccactacctctgt & X04957|TRAV27*02 \\
\hline actccgctgtgtacttctgt & AE000659|TRAV9-1*01 \\
\hline actcagccacctacctctgt & $\begin{array}{l}\text { X58736|TRAV21*02 } \\
\text { AE000660|TRAV21*01 }\end{array}$ \\
\hline atacaggcctctacctctgt & $\begin{array}{l}\text { AE000660|TRAV27*01 } \\
\text { D13075|TRAV27*03 }\end{array}$ \\
\hline actctgccgtgtactactgc & AE000660|TRAV18*01 \\
\hline actcagctgtctacttttgt & $\begin{array}{l}\text { M17658|TRAV13-2*02 } \\
\text { AE000659|TRAV13-2*01 }\end{array}$ \\
\hline actcagcaatgtatttctgt & $\begin{array}{l}\text { AE000659|TRAV14/DV4*02 } \\
\text { M21624|TRAV14/DV4*03 }\end{array}$ \\
\hline atgtaggaacctacttctgt & AE000660|TRAV25*01 \\
\hline attcagccacctatttctgt & AE000659|TRAV7*01 \\
\hline atgcaggcatctacctctgt & AE000660|TRAV34*01 \\
\hline acacagctgagtacttctgt & AE000659|TRAV8-1*01 \\
\hline attcagccacatacctctgt & M17661|TRAV24*02 \\
\hline atgtaggcatctacttctgt & $\begin{array}{l}\text { AE000660|TRAV35*01 } \\
\text { X58738|TRAV35*02 }\end{array}$ \\
\hline acgcggctgagtacttctgt & $\begin{array}{l}\text { M12959|TRAV8-4*04 } \\
\text { X63455|TRAV8-4*05 } \\
\text { M17650|TRAV8-2*02 } \\
\text { M12423|TRAV8-4*02 } \\
\text { D13077|TRAV8-4*03 } \\
\text { AE000659|TRAV8-2*01 } \\
\text { AE000659|TRAV8-4*01 } \\
\text { K02777|TRAV8-4*06 }\end{array}$ \\
\hline actcaggcgtttatttctgt & AE000660|TRAV22*01 \\
\hline actcggecgtctacctctgt & $\begin{array}{l}\text { Z46643|TRAV36/DV7*04 } \\
\text { X58767|TRAV36/DV7*03 } \\
\text { X61070|TRAV36/DV7*02 }\end{array}$ \\
\hline acactgcgatgtatttctgt & $\begin{array}{l}\text { AE000661|TRAV38-1*01 } \\
\text { L06880|TRAV38-1*04 } \\
\text { M95394|TRAV38-1*03 }\end{array}$ \\
\hline
\end{tabular}




\begin{tabular}{|c|c|}
\hline & M64355|TRAV38-1*02 \\
\hline actcagcaatgtacttctgt & M21626|TRAV14/DV4*01 \\
\hline actcagcagtatacttctgt & AE000660|TRAV19*01 \\
\hline actcagccgtgtactactgt & X73521|TRAV40*01 \\
\hline acacggctgagtacttctgt & $\begin{array}{l}\text { X02850|TRAV8-6*01 } \\
\text { AE000659|TRAV8-6*02 }\end{array}$ \\
\hline actcagccacatacctctgt & AE000660|TRAV24*01 \\
\hline actcagctacctacctctgt & $\begin{array}{l}\text { AE000659|TRAV6*01 } \\
\text { X58747|TRAV6*02 } \\
\text { Z49060|TRAV6*03 } \\
\text { Y10410|TRAV6*05 } \\
\text { Y10409|TRAV6 } 04 \\
\end{array}$ \\
\hline actctgcagtgtacttctgt & $\begin{array}{l}\text { S81645|TRAV29/DV5*02 } \\
\text { AE000660|TRAV29/DV5*01 }\end{array}$ \\
\hline acactgctgtgtactattgc & $\begin{array}{l}\text { AE000660|TRAV26-1*01 } \\
\text { M27371|TRAV26-1*02 } \\
\text { L06886|TRAV26-1*03 }\end{array}$ \\
\hline actcggccatctacctctgt & AE000660|TRAV36/DV7*01 \\
\hline actctgcctcttacttctgc & $\begin{array}{l}\text { X04939|TRAV1-1*02 } \\
\text { AE000658|TRAV1-1*01 }\end{array}$ \\
\hline tctctgccacctacttctgt & AE000661|TRAV39*01 \\
\hline actctgcctcttacctctgt & AE000658|TRAV1-2*01 \\
\hline acactgctgtgtactactgc & AE000658|TRAV4*01 \\
\hline actccgctttgtacttctgt & AE000658|TRAV3*01 \\
\hline actcagccacttatctctgt & $\begin{array}{l}\text { X70305|TRAV20*04 } \\
\text { S60789|TRAV20*03 } \\
\text { AE000660|TRAV20*01 } \\
\text { X68696|TRAV20*02 }\end{array}$ \\
\hline atgctgctgtttactactgt & $\begin{array}{l}\text { AE000658|TRAV2*01 } \\
\text { M17659|TRAV2*02 }\end{array}$ \\
\hline acccggctgagtacttctgt & M17665|TRAV8-4*07 \\
\hline attcagccacctacctctgt & $\begin{array}{l}\text { AE000659|TRAV12-2*01 } \\
\text { AE000659|TRAV12-1*01 } \\
\text { M17657|TRAV12-1*02 } \\
\text { M17656|TRAV12-3*02 } \\
\text { M81774|TRAV12-2*02 } \\
\text { X04946|TRAV12-2*03 } \\
\text { AE000659|TRAV12-3*01 }\end{array}$ \\
\hline actctgccgtctacatctgt & AE000661|TRAV41*01 \\
\hline actcaggaacctacttctgc & $\begin{array}{l}\text { L06883|TRAV30*03 } \\
\text { AE000660|TRAV30*01 } \\
\text { X58768|TRAV30*02 }\end{array}$ \\
\hline atgccgcgatgtatttctgt & AE000661|TRAV38-2/DV8*01 \\
\hline attcagcctcctacatctgt & AE000659|TRAV10*01 \\
\hline actcggctgtctacttctgt & $\begin{array}{l}\text { AE000659|TRAV13-1*01 } \\
\text { X04954|TRAV13-1*02 }\end{array}$ \\
\hline acactgcttcttacttctgt & AE000660|TRAV17*01 \\
\hline actcagcggtgtacttctgt & $\begin{array}{l}\text { L06882|TRAV9-2*04 } \\
\text { X58745|TRAV9-2*02 } \\
\text { L06881|TRAV9-2*03 }\end{array}$ \\
\hline
\end{tabular}


bioRxiv preprint doi: https://doi.org/10.1101/494062; this version posted February 5, 2020. The copyright holder for this preprint (which was not certified by peer review) is the author/funder, who has granted bioRxiv a license to display the preprint in perpetuity. It is made available under aCC-BY-NC-ND 4.0 International license.

\begin{tabular}{|c|c|}
\hline & AE000659|TRAV9-2*01 \\
\hline actcagccatgtattactgt & AE000659|TRAV16*01 \\
\hline \multicolumn{2}{|c|}{ 1MM: human TCRA FR3 primers } \\
\hline \multicolumn{2}{|l|}{ actccgctgtgtacttctgt } \\
\hline \multicolumn{2}{|l|}{ actcagcggtgtacttctgt } \\
\hline \multicolumn{2}{|l|}{ actcggecgtctacctctgt } \\
\hline \multicolumn{2}{|l|}{ actcagccacctacctctgt } \\
\hline \multicolumn{2}{|l|}{ acgcggctgagtacttctgt } \\
\hline \multicolumn{2}{|l|}{ actcagcagtatacttctgt } \\
\hline \multicolumn{2}{|l|}{ actcagctatctacttctgt } \\
\hline \multicolumn{2}{|l|}{ actctgccgtctacatctgt } \\
\hline \multicolumn{2}{|l|}{ actcagcaatgtacttctgt } \\
\hline \multicolumn{2}{|l|}{ actctgccgtgtactactgc } \\
\hline \multicolumn{2}{|l|}{ acactgcttcttacttctgt } \\
\hline \multicolumn{2}{|l|}{ attcagccacctatttctgt } \\
\hline \multicolumn{2}{|l|}{ actctgcctcttacctctgt } \\
\hline \multicolumn{2}{|l|}{ actcggctgtctacttctgt } \\
\hline \multicolumn{2}{|l|}{ atacaggcctctacctctgt } \\
\hline \multicolumn{2}{|l|}{ actcagccgtgtactactgt } \\
\hline \multicolumn{2}{|l|}{ acactgcgatgtatttctgt } \\
\hline \multicolumn{2}{|l|}{ atgctgctgtgtactactgc } \\
\hline \multicolumn{2}{|l|}{ attcagcctcctacatctgt } \\
\hline \multicolumn{2}{|l|}{ actctgcagtgtacttctgt } \\
\hline \multicolumn{2}{|l|}{ atgccgcgatgtatttctgt } \\
\hline \multicolumn{2}{|l|}{ atgctgctgtttactactgt } \\
\hline \multicolumn{2}{|l|}{ actcagccacttatctctgt } \\
\hline acactgctgtgtactactgc & \\
\hline atgcaggcatctacctctgt & \\
\hline actcagccatgtattactgt & \\
\hline actctgcctcttacttctgc & \\
\hline atgtaggcatctacttctgt & \\
\hline acactgctgtgtactattgc & \\
\hline actcaggcgtttatttctgt & \\
\hline actcagctgtctacttttgt & \\
\hline actcaggaacctacttctgc & \\
\hline atgcgtctgagtacttctgt & \\
\hline atgctgctgagtacttctgt & \\
\hline atgtaggaacctacttctgt & \\
\hline acacagctgagtacttctgt & \\
\hline tctctgccacctacttctgt & \\
\hline attcagccacatacctctgt & \\
\hline & act: human TCRA FR3 primers \\
\hline actcigcigtitacttctgt & \\
\hline actcagccaittacitctgt & \\
\hline acicigctgagtacttctgt & \\
\hline actcagccitgtaitictgt & \\
\hline actctgccgittactictgc & \\
\hline aticaggciictacctctgt & \\
\hline aiictgctgtgtactaitgc & \\
\hline
\end{tabular}




\begin{tabular}{|c|c|}
\hline gaattccttcaccagacaagcgac & Reverse transcription \\
\hline ccagacaagcgacatttgttcc & Reverse primer: PCRI \\
\hline \multicolumn{2}{|c|}{ Full: human TCRD FR3 primers } \\
\hline Primer Sequence & $\begin{array}{l}\text { IMGT Accession I } \\
\text { Associated V allele }\end{array}$ \\
\hline attcagcaaggtacttttgt & M22198|TRDV1*01 \\
\hline atgccgcgatgtatttctgt & AE000661|TRAV38-2/DV8*01 \\
\hline actctgcagtgtacttctgt & $\begin{array}{l}\text { S81645|TRAV29/DV5*02 } \\
\text { AE000660|TRAV29/DV5*01 }\end{array}$ \\
\hline actcggccatctacctctgt & AE000660|TRAV36/DV7*01 \\
\hline actcagccacctacttctgt & $\begin{array}{l}\text { M97704|TRAV23/DV6*03 } \\
\text { Y10411|TRAV23/DV6*04 } \\
\text { AE000660|TRAV23/DV6*01 } \\
\text { M17660|TRAV23/DV6*02 }\end{array}$ \\
\hline actcagcaatgtatttctgt & $\begin{array}{l}\text { AE000659|TRAV14/DV4*02 } \\
\text { M21624|TRAV14/DV4*03 }\end{array}$ \\
\hline actcggccgtctacctctgt & $\begin{array}{l}\text { Z46643|TRAV36/DV7*04 } \\
\text { X58767|TRAV36/DV7*03 } \\
\text { X61070|TRAV36/DV7*02 }\end{array}$ \\
\hline acagtgccacttactactgt & $\begin{array}{l}\text { M23326|TRDV3*01 } \\
\text { X15261|TRDV3*02 }\end{array}$ \\
\hline atgaagggtcttactactgt & $\begin{array}{l}\text { X15207|TRDV2*01 } \\
\text { Y13426|TRDV2*02 } \\
\text { AE000661|TRDV2*03 }\end{array}$ \\
\hline actcagcaatgtacttctgt & M21626|TRAV14/DV4*01 \\
\hline \multicolumn{2}{|c|}{ 1MM: human TCRD FR3 primers } \\
\hline \multicolumn{2}{|l|}{ actcggccgtctacctctgt } \\
\hline \multicolumn{2}{|l|}{ actcagcaatgtacttctgt } \\
\hline \multicolumn{2}{|l|}{ actctgcagtgtacttctgt } \\
\hline \multicolumn{2}{|l|}{ atgccgcgatgtatttctgt } \\
\hline \multicolumn{2}{|l|}{ atgaagggtcttactactgt } \\
\hline \multicolumn{2}{|l|}{ actcagccacctacttctgt } \\
\hline \multicolumn{2}{|l|}{ acagtgccacttactactgt } \\
\hline \multicolumn{2}{|l|}{ attcagcaagtacttttgt } \\
\hline \multicolumn{2}{|c|}{ Compact: human TCRD FR3 primers } \\
\hline \multicolumn{2}{|c|}{ actcggccitctacctctgt } \\
\hline \multicolumn{2}{|l|}{ actcagcaaiitaittctgt } \\
\hline \multicolumn{2}{|l|}{ atgccgcgatgtatttctgt } \\
\hline \multicolumn{2}{|l|}{ actctgcagtgtacttctgt } \\
\hline \multicolumn{2}{|l|}{ atgaagggtcttactactgt } \\
\hline \multicolumn{2}{|l|}{ acagtgccacttactactgt } \\
\hline attcagcaagtacttttgt & \\
\hline
\end{tabular}

642 Table S7: Human TCRA, TCRG, and TCRD FR3AK-seq primers. Adapter sequences can be found in 


\begin{tabular}{|c|c|}
\hline \multicolumn{2}{|c|}{ Table S8: FR3AK-seq human TCRB J region primers } \\
\hline Primer Sequence & $\begin{array}{l}\text { IMGT Accession | } \\
\text { Associated J allele }\end{array}$ \\
\hline ccagcactgagagccgggtc & X02987|TRBJ2-4*01 \\
\hline ccagaaccaggagtcctccg & X02987|TRBJ2-2P*01 \\
\hline cgagcaccaggagccgcgtg & X02987|TRBJ2-5*01 \\
\hline ccagtacggtcagcctagag & X02987|TRBJ2-2*01 \\
\hline cgagcactgtcagccgggtg & X02987|TRBJ2-3*01 \\
\hline ctgtgaccgtgagcctggtg & $\begin{array}{l}\text { X02987|TRBJ2-7*02 } \\
\text { M14159|TRBJ2-7*01 }\end{array}$ \\
\hline ctacaacggttaacctggtc & K02545|TRBJ1-2*01 \\
\hline ctacaacagtgagccaactt & M14158|TRBJ1-3*01 \\
\hline ctgtcacagtgagcctggtc & $\begin{array}{l}\text { M14158|TRBJ1-6*01 } \\
\text { L36092|TRBJ1-6*02 }\end{array}$ \\
\hline ctacaactgtgagtctggtg & K02545|TRBJ1-1*01 \\
\hline ctaggatggagagtcgagtc & M14158|TRBJ1-5*01 \\
\hline ccaagacagagagctgggtt & M14158|TRBJ1-4*01 \\
\hline ccagcacggtcagcctgctg & X02987|TRBJ2-6*01 \\
\hline ctagcacggtgagccgtgtc & X02987|TRBJ2-1*01 \\
\hline
\end{tabular}




\begin{tabular}{|c|c|}
\hline \multicolumn{2}{|c|}{ Table S9: Software parameters } \\
\hline \multicolumn{2}{|c|}{ MiXCR v2.1.11 } \\
\hline Parameter & Rationale \\
\hline assemble - OaddReadsCountOnClustering=true & $\begin{array}{l}\text { makes error correction algorithms to } \\
\text { combine clone abundancies (all } \\
\text { "children" clone counts added to head } \\
\text { clone) }\end{array}$ \\
\hline assemble --index & $\begin{array}{l}\text { For IIM samples only; links reads in } \\
\text { fastq file to CDR3s }\end{array}$ \\
\hline exportClones --chains TRB & exports TCRB chain sequences only \\
\hline \multicolumn{2}{|c|}{ GLIPH 1.0} \\
\hline $\begin{array}{l}\text { Algorithm step } \\
\text {--inputs required }\end{array}$ & $\begin{array}{l}\text { Parameters } \\
\text { Input file(s) column names }\end{array}$ \\
\hline $\begin{array}{l}\text { 1) ./gliph/bin/gliph-group-discovery.pl } \\
\text {--tcr TCR_TABLE }\end{array}$ & $\begin{array}{l}\text { default } \\
\text { TCR_TABLE = only CDR3b sequences }\end{array}$ \\
\hline 2)./gliph/bin/gliph-group-scoring.pl & default \\
\hline $\begin{array}{l}\text {--convergence_file TCR_TABLE-convergence- } \\
\text { groups.txt }\end{array}$ & $\begin{array}{l}\text { TCR_TABLE-convergence-groups.txt } \\
=\text { from step } 1\end{array}$ \\
\hline --clone_annotations FULL_TCR_TABLE & $\begin{array}{l}\text { FULL_TCR_TABLE = CDR3b, Patient, } \\
\text { Counts }\end{array}$ \\
\hline --motif_pval_file TCR_TABLE.minp.ove10.txt & $\begin{array}{l}\text { TCR_TABLE.minp.ove10.txt Counts = } \\
\text { from step } 1\end{array}$ \\
\hline
\end{tabular}

Table S9: MiXCR and GLIPH parameters used in analysis. Default parameters were used except as noted. algorithm was used to match patient and counts with original CDR3b sequences.

Table S10: Summary of Donor A clones across platforms

\begin{tabular}{|l|c|c|c|}
\hline \multicolumn{4}{|c|}{ Table S10: Summary of Donor A clones across platforms } \\
\hline Platform & $\begin{array}{c}\text { ImmunoSEQ } \\
\text { hsTCRB service } \\
\text { (Adaptive } \\
\text { Biotechnologies) }\end{array}$ & $\begin{array}{c}\text { Immunoverse } \\
\text { (ArcherDx) }\end{array}$ & FR3AK-seq \\
\hline Total clones detected & 394797 & 67274 & 362288 \\
\hline $\begin{array}{l}\text { Number of singletons } \\
\text { (clone count =1) }\end{array}$ & 345880 & 20570 (pre-deduplication) & 198635 \\
\hline $\begin{array}{l}\text { Number of clones } \\
\text { present at } \geq 10 \\
\text { counts }\end{array}$ & 2702 & $\begin{array}{c}10689 \text { (pre-deduplication) } \\
1080 \text { (post-deduplication) }\end{array}$ & 7189 \\
\hline
\end{tabular}

Table S10: Summary of Donor A CDR3 sequences detected across platforms. 